\title{
1 Multiple drivers of seasonal change in PRI: Implications for photosynthesis
}

\section{2 \\ 2. Stand level}

3

4 Anatoly A. Gitelson ${ }^{\varepsilon^{*}}$, John A. Gamon ${ }^{\mu}$, Alexei Solovchenko ${ }^{\phi}$

$5{ }^{\varepsilon}$ Faculty of Civil and Environmental Engineering, Israel Institute of Technology, Technion City,

6 Haifa, Israel

$7 \quad{ }^{\mu}$ Departments of Earth \& Atmospheric Sciences and Biological Sciences, 1-26 Earth Sciences

8 Building, University of Alberta, Canada (Current address: School of Natural Resources,

9 University of Nebraska - Lincoln, 307 Hardin Hall, 3310 Holdrege St., Lincoln, NE, 68583-

$10 \quad 0989$ USA

$11{ }^{\phi}$ Department of Bioengineering, Faculty of Biology, M.V. Lomonosov Moscow State University

12 1/12 Leninskie Gori, Moscow, Russia

14 * Corresponding author, agitelson2@unl.edu

\section{Abstract}

The goal of this study was to explore the relationships between stand-level photochemical reflectance index (PRI) and canopy structure/pigment pools, as well as light use efficiency (LUE) of photosynthetically active vegetation focusing on seasonal or ontogenetic time frames. PRI was

20 originally designed as a means of assessing the xanthophyll cycle and LUE over short (e.g. diurnal)

21 time frames, and few studies have explored the drivers of PRI over longer, seasonal time frames,

22 particularly in crops having different photosynthetic pathways or canopy structures. Consequently, 23 our purpose was to understand and quantify the drivers of PRI responses over seasonal time scales 
24 for two crops, maize $\left(\mathrm{C}_{4}\right)$ and soybean $\left(\mathrm{C}_{3}\right)$, contrasting in photosynthetic pathway, leaf structure 25 and canopy architecture. In both crops, PRI was very closely related to green LAI $\left(R^{2}>0.90\right)$ and stand chlorophyll $(\mathrm{Chl})$ content $\left(\mathrm{R}^{2}>0.93\right)$. The slopes of the relationships in different

27 phenological stages, vegetative and reproductive, were substantially different (3-fold smaller in the vegetative stage). The main cause of this disparity was the high PRI value of soil / residue background. While PRI was a sensitive indicator of the changes in stand green LAI and stand Chl content over the full growing season, it was not sensitive to LUE; LUE explained below $12 \%$ of PRI variation in maize and $19 \%$ in soybean. Unlike leaf-level PRI, stand-level PRI was not 32 clearly related to the $\mathrm{Car} / \mathrm{Chl}$ ratio, presumably because the large changes in canopy structure (affecting stand Chl and green LAI) had a dominant influence on PRI over this time frame. The strong relationship between PRI and stand Chl content as well as between PRI and Chl-related vegetation index over a growing cycle allowed us to subtract the stand Chl content effect from measured PRI to reveal the component of PRI most likely related to periods of stress. However, for accurate subtraction of the Chl effect from long-term PRI records, thoughtful study of uncertainties related to "natural" variation of PRI-stand Chl relationships, and stand Chl content estimation for different varieties of the same species and for different species is required. The findings of a strong link between stand-level PRI and stand green LAI and Chl content and the lack of a clear relationship between PRI and LUE over seasonal and ontogenetic time spans suggest the need for a more careful evaluation of the relationship between PRI and either LUE or photosynthetic activity. In particular, studies that contrast short-term (e.g. diurnal) vs. long-term (e.g. seasonal) pigment, PRI, and photosynthetic responses in contrasting vegetation types are needed to clarify the different mechanisms involved at different temporal and spatial scales. These 
findings have important implications for attempts to monitor photosynthetic phenology from remote sensing, many of which have relied on PRI as an indicator of photosynthetic activity.

Key words: chlorophyll, carotenoids, xanthophyll cycle, leaf area.

\section{Introduction}

Much of the foundational work on the photochemical reflectance index (PRI) was done on leaves and closed-canopy stands, demonstrating a strong link between PRI, xanthophyll cycle 54 activity, and photosynthetic light-use efficiency (LUE) over diurnal time scales (Gamon et al. 1992, Peñuelas et al. 2005, Gamon et al. 1997). Expanding this interpretation of PRI to larger

56 spatial scales and longer temporal scales has been a challenge. Several studies have compared 57 leaf-level to canopy-level PRI and have found a close relationship between the two for dense 58 monocultural stands suggesting that a closed-canopy stand approximates a "big leaf" in terms of the PRI signal (e.g. Stylinski et al., 2002, Gamon and Qiu, 1999, Wong and Gamon, 2015b, Gamon, 2015). However, when expanding to the full seasonal time scale, the interpretation of

61 PRI often remains unclear because few long-term studies explicitly compare PRI to many factors

62 that can affect this signal (see Barton and North, (2001) for examples of these potentially

63 confounding factors). Over seasonal time scales, especially for annual vegetation that undergoes

64 large changes in canopy structure, greening and senescence, the seasonal change in green canopy 65 display can have a dominant influence on the PRI signal. While relatively few long-term remote 66 sensing studies of PRI explicitly link this index to xanthophyll cycle activity, many studies have 67 reported a correlation between PRI and LUE (Nichol et al. 2002, Rahman et al., 2004, Drolet et 68 al., 2005, Goerner et al., 2011, Garbulsky et al., 2011), but the exact reasons remain obscure due 
to the many factors that affect the PRI signal at these scales (Barton and North, 2001) and due to

70 the different operational definitions of LUE (Gitelson \& Gamon 2015). Understanding the

71 underlying reasons for these correlations between LUE and PRI from aircraft or satellite data is

72 critical to implementing defensible LUE models from remote sensing that incorporate PRI.

73 Modeling studies (Barton and North, 2001) suggests many potentially complicating factors

74 when trying to apply PRI to whole stands in a remote sensing context. Among them, the effects

75 of canopy structure, including green leaf area index (LAI), the degree of canopy closure and soil

76 background contribution to the reflectance signal are known to strongly affect PRI. Additionally,

77 angular effects, including leaf angle distribution and sun-target-sensor sampling geometry can

78 have a significant influence on the PRI signal and its interpretation (Barton and North, 2001,

79 Drolet et al., 2005, Gamon, 2015). As predicted by modeling (Barton and North, 2001), previous empirical studies have found a strong correlation between PRI and green canopy cover as

81 measured by NDVI (Gamon et al., 1995), indicating a strong influence of green canopy structure

82 on the PRI signal. Because these structural effects also influence the overall stand photosynthetic

83 rate, they can potentially influence the PRI-photosynthesis relationship independently of the

84 xanthophyll cycle activity, creating an ill-conditioned situation when interpreting PRI. There are

85 few published, long-term studies examining how PRI is affected by canopy structure over the

86 annual growth cycle of a vegetation stand, leaving this topic relatively unexplored.

87 In addition to canopy structure, leaf pigmentation, which can change gradually with leaf

88 development and senescence, clearly affects PRI (Gamon et al. 2001, Sims and Gamon 2002,

89 Garrity et al. 2011, Gitelson et al. - the companion paper in review). In an attempt to discern the

90 short-term effects from the longer-term effects, Gamon and Berry, (2012) classified PRI

91 responses to pigmentation in evergreens into "facultative" (xanthophyll cycle-driven effects 
92 operating over the diurnal time scale) and "constitutive" (changing pigment pool sizes over

93 seasonal time scales, e.g. due to ontogeny and senescence and/or in response to resource levels).

94 Several studies have now confirmed that long-term (seasonal) PRI responses at the leaf level are

95 primarily driven by constitutive pigment pool size changes, and not facultative xanthophyll cycle

96 activity (Stylinski et al., 2002, Sims et al., 2006, Filella et al., 2009, Gamon and Berry, 2012,

97 Wong and Gamon, 2015A and B). These studies have primarily considered evergreen responses,

98 leaving long-term PRI responses less-well characterized for deciduous and annual vegetation

99 (e.g. crops). Because pigment content can also be tied to photosynthetic capacity and LUE, there

100 may be multiple reasons why PRI often correlates with photosynthetic activity (Garbulsky et al.,

101 2011, Gamon, 2015), creating an overdetermined situation that easily leads to misunderstanding

102 of mechanism. Further clarification of these different pigment effects against a background of

103 changing canopy structure is an essential step toward understanding PRI responses in a long-

104 term monitoring campaign, particularly for deciduous and annual plants (e.g. crops) where long-

105 term responses have been less-well studied.

106 Given the potential for PRI to provide a useful metric of LUE, a full understanding of

107 multiple confounding variables is needed. In a companion paper, we established relationships

108 between PRI and foliar pigment content and composition (Gitelson et al., 2016). The goal of this

109 current study at a larger scale was to explore the relationships between stand-level PRI and canopy

110 structure/pigment pools, as well as LUE of photosynthetically active vegetation focusing on

111 seasonal or ontogenetic time frames. The purpose was to understand and quantify the drivers of

112 PRI responses over seasonal time scales for two crops $\left(\mathrm{C}_{3}\right.$ and $\left.\mathrm{C}_{4}\right)$, contrasting in photosynthetic

113 pathway, leaf structure and canopy architecture. A key point was to evaluate how the PRI signal

114 over the growing cycle is influenced by changes in canopy structure and pigment pools 
115 associated with changing crop phenology and physiology and compare it with seasonal change in 116 LUE.

\section{2. Methods.}

118 The study site was located at the University of Nebraska-Lincoln Agricultural Research and 119 Development Center near Mead, Nebraska. This study site consists of three 65-ha fields. Each 120 field was managed as either continuous irrigated maize, irrigated maize/soybean rotation, or 121 rainfed maize (Zea mays)/soybean (Glycine max) rotation following the best management 122 practices (e.g. fertilization, herbicide/pesticide treatment) for eastern Nebraska for its respective 123 planting cycle. There were a total of 24 field-years for maize and soybean. Maximal green LAI 124 values ranged from 4.3 to $6.5 \mathrm{~m}^{2} \mathrm{~m}^{-2}$ for maize and 3.0 to $5.5 \mathrm{~m}^{2} \mathrm{~m}^{-2}$ for soybean (details are in 125 Verma et al., 2005 and Viña et al., 2011). Incoming PAR and fraction of radiation absorbed by photosynthetically active vegetation. In

127 each study site quantum sensors were placed to collect hourly incoming PAR (PAR in $_{\text {) }}$ PAR 128 reflected by the canopy and soil ( $\left.\mathrm{PAR}_{\text {out }}\right)$, PAR transmitted through the canopy $\left(\mathrm{PAR}_{\text {transm }}\right)$ and 129 PAR reflected by the soil $\left(\mathrm{PAR}_{\text {soil }}\right)$. $\mathrm{PAR}_{\text {in }}$ was measured $6 \mathrm{~m}$ above the surface by point 130 quantum sensors (Model LI-190, Li-Cor Inc., Lincoln, Nebraska) pointing towards the sky. 131 Daytime $\mathrm{PAR}_{\text {in }}$ were calculated by integrating the hourly measurements during a day from 132 sunrise to sunset (period when $\mathrm{PAR}_{\text {in }}$ exceeding $1 \mu \mathrm{mol} \mathrm{m} \mathrm{m}^{-2} \mathrm{~s}^{-1}$ ).

$133 \quad \mathrm{PAR}_{\text {out }}$ was measured at $6 \mathrm{~m}$ above the ground by point quantum sensors aimed downward; 134 PAR $_{\text {transm }}$ was measured at about $2 \mathrm{~cm}$ above the ground with line quantum sensors (Model LI135 191, Li-Cor Inc., Lincoln, Nebraska) pointing upward. PAR soil was measured about $12 \mathrm{~cm}$ above 136 the ground with line quantum sensors pointing downward. All daily values of radiation were 137 computed by integrating the hourly measurements during a day when hourly PAR $_{\text {in }}$ exceeded 1 
$138 \mu \mathrm{mol} \mathrm{m} \mathrm{m}^{-2}$. Daily values of the fraction of PAR absorbed by the whole canopy (fAPAR total $_{\text {) }}$

139 were then calculated as (Viña and Gitelson, 2005):

$140 \quad \mathrm{fAPAR}_{\text {total }}=\left(\mathrm{PAR}_{\text {in }}-\mathrm{PAR}_{\text {out }}-\mathrm{PAR}_{\text {transm }}+\mathrm{PAR}_{\text {soil }}\right) / \mathrm{PAR}_{\text {in }}$

141 To obtain a measure of the fAPAR absorbed solely by the photosynthetic component of the

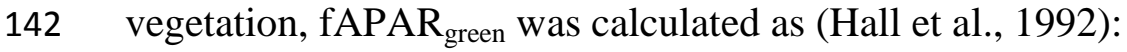

$143 \mathrm{fAPAR}_{\text {green }}=\mathrm{fAPAR}_{\text {total }} \times\left(\mathrm{LAI}_{\text {green }} /\right.$ total LAI $)$.

144 Gross primary production, absorbed PAR and light use efficiency. GPP was measured by the

145 eddy covariance method. Each site was equipped with an eddy covariance tower and

146 meteorological sensors, with which measurements of $\mathrm{CO}_{2}$ fluxes, water vapor, and energy fluxes

147 were obtained continuously. Daytime net ecosystem exchange (NEE) values were calculated by

148 integrating hourly $\mathrm{CO}_{2}$ fluxes when $\mathrm{PAR}_{\text {in }}$ exceeded $1 \mu \mathrm{mol} \mathrm{m} \mathrm{m}^{-2}$. Daytime ecosystem

149 respiration $(\mathrm{Re})$ were obtained from the night $\mathrm{CO}_{2}$ exchange-temperature relationship (e.g., $\mathrm{Xu}$

150 and Baldocchi, 2003). GPP was then obtained by subtracting Re from NEE as: GPP = NEE - Re.

151 Daytime PAR absorbed by the canopy $\left(\mathrm{aPAR}_{\text {total }}\right)$ was calculated as the product of fAPAR total

152 and daytime $\mathrm{PAR}_{\text {in }}: \mathrm{aPAR}_{\text {total }}=\mathrm{fAPAR}_{\text {total }} \times \mathrm{PAR}_{\text {in }} . \mathrm{PAR}$ absorbed by the photosynthetic

153 component of the vegetation was calculated as $\mathrm{aPAR}_{\text {green }}=\mathrm{fAPAR}_{\text {green }} \times \mathrm{PAR}_{\mathrm{in}}$.

154 LUE of photosynthetically active vegetation ( $\mathrm{LUE}_{\text {green }}$ ), which is a quantitative measure of

155 the efficiency of conversion of $\mathrm{APAR}_{\text {green }}$ into fixed carbon (Gitelson and Gamon, 2015) was

156 calculated as (Monteith, 1972; Monteith and Moss, 1977):

$157 \quad \mathrm{LUE}_{\text {green }}=\mathrm{GPP} / \mathrm{aPAR}$ green

158 Green LAI. Within each of three fields, six small plot areas $(20 \mathrm{~m} \times 20 \mathrm{~m})$ were established.

159 They represented major occurrences of soil and crop production zones within each field (Verma

160 et al., 2005). LAI was measured from destructive samples at 10-14 day intervals during the 
161 growing seasons 2001 through 2008. On each sampling date, plants from a 1-m length of either

162 of two rows within each plot were collected and the total number of plants recorded. Plants were

163 kept on ice and transported to the laboratory where they were separated into green leaves, dead

164 leaves, and litter components. All leaves were run through an area meter (Model LI-3100, Li-

165 Cor, Inc., Lincoln, Nebraska) and the leaf area per plant was determined. For each plot, the leaf

166 area per plant was multiplied by the plant density to obtain a total LAI. Total LAI values for the

167 six plots were then averaged as a site-level value (details in Viña et al., 2011). Green leaves were

168 measured in the same way to obtain the green LAI.

169 Total canopy $\mathrm{Chl}$ content was estimated as $\mathrm{Chl}=\mathrm{Chl}_{\text {leaf }} \times$ total $\mathrm{LAI}$, where $\mathrm{Chl}_{\text {leaf }}$ is the $\mathrm{Chl}$

170 content of the upper-most collared or ear leaf in maize and upper leaf in soybean. Adaxial

171 reflectance of the crop leaves was measured in the spectral range from $400 \mathrm{~nm}$ to $900 \mathrm{~nm}$ using a

172 Mini Leaf Clip (UNI501, PP Systems, Amesbury MA, USA) with a 2.3-mm-diameter bifurcated

173 fiber-optic cable attached to both a spectroradiometer (USB2000, Ocean Optics, Dunedin FL,

174 USA) and to a tungsten halogen light source (LS-1, Ocean Optics). A 99\% reflectance standard

175 (Spectralon, LabSphere, North Sutton NH, USA) was scanned before and after each leaf

176 measurement. The reflectance was calculated as the ratio of upwelling leaf radiance to the

177 upwelling radiance of the standard (details are in Gitelson et al., 2005, Ciganda et al., 2009).

178 A red-edge chlorophyll index $\mathrm{CI}_{\text {red edge }}=\left(\rho_{\mathrm{NIR}} / \rho_{\text {red edge }}-1\right)$, where $\rho_{\mathrm{NIR}}$ and $\rho_{\text {red edge }}$ are

179 reflectance in the range $770-800 \mathrm{~nm}$ and $720-730 \mathrm{~nm}$, respectively, was used for estimating leaf

180 Chl content. RMSE of Chl content prediction by $\mathrm{CI}_{\text {red edge }}$ was $38 \mathrm{mg} \mathrm{m}^{-2}$ in the range of Chl

181 content 22-880 $\mathrm{mg} \mathrm{m}^{-2}$ by (details in Gitelson et al., 2003, 2006; Ciganda et al., 2009). The stand

182 reflectance measurements and ground measurements were not always concurrent and, since LAI

183 and leaf Chl content changed gradually, spline interpolations were taken between destructive 
184 LAI sampling dates for each field in each year using Matlab (V. 7.9.0.529, The MathWorks, 185 Massachusetts, USA) (Nguy-Robertson et al., 2012).

186 The hyperspectral data were collected from 2001 to 2008 using an all-terrain sensor platform 187 (Rundquist et al., 2004; 2014). Two spectroradiometers (USB2000 Ocean Optics, Inc., Dunedin 188 FL, USA) were used to collect reflectance in the range 400 to $1100 \mathrm{~nm}$ with about $1.5 \mathrm{~nm}$ 189 resolution. The downwelling fiber was fitted with a cosine diffuser to detect incident irradiance; 190 the upwelling fiber measured canopy radiance. A field of view of the upwelling fiber was 191 approximately $2.4 \mathrm{~m}$ in diameter; the distance between the fiber and the top of canopy was 192 constant throughout the growing season. The mean of 36 reflectance spectra collected in each 193 field was used as the stand-level reflectance measurement. A total of 278 spectra for maize and 194145 for soybean were acquired in 2001 through 2008 (Viña et al., 2011; Nguy-Robertson et al., $1952012,2014)$.

197 Results and Discussion

198 The relationships between PRI and green LAI (PRI-LAI), and PRI and stand Chl content 199 (PRI-Chl) for two contrasting in photosynthetic pathways, leaf structure, and canopy architecture 200 crops, maize and soybean, were investigated. The temporal behavior of PRI (scaled between 0 201 and 1) and green LAI for maize and soybean is shown in Fig. 1. In the beginning of the growing 202 season PRI was around 40 to $50 \%$ of its maximal value in both crops and increased as the crop 203 developed, reaching its maximal value at the time of maximal green LAI. The main drivers of 204 PRI in the vegetative stage appeared to be the increasing green LAI, green vegetation cover and 205 leaf Chl content, causing a sharp decrease in reflectance at both wavelengths used in PRI, $\rho_{530}$ 206 and $\rho_{570}$, and, thus, decrease in denominator of PRI, $(\rho 530+\rho 570)$ (Figs. 2A and 3, DOY $140-$ 
beginning of the season, DOY 200 - top of the season). The numerator of PRI, $(\rho 530-\rho 570)$, canopy development in the vegetative stage the dynamic range of PRI was narrower than the dynamic range of green LAI (Fig. 1). The main reason for that was the high PRI value for

211 soil/residue (as evidenced by the reflectance values at day 140 in Figure 2A on the PRI wave 212 bands), which contributed to the stand reflectance signal in the early growth stages. Modeling studies have also indicated high sensitivity of PRI to soil background (Barton and North, 2001).

214 215

216
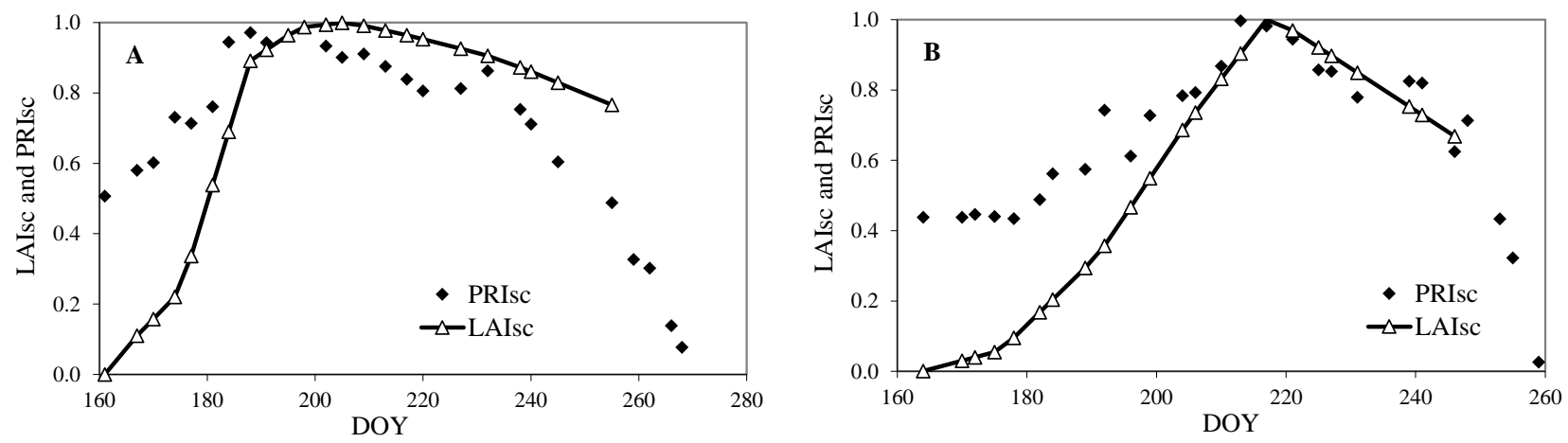

Fig. 1. Temporal behavior of scaled (between 0 and 1) green LAI and PRI of maize (A) and soybean $(B)$.
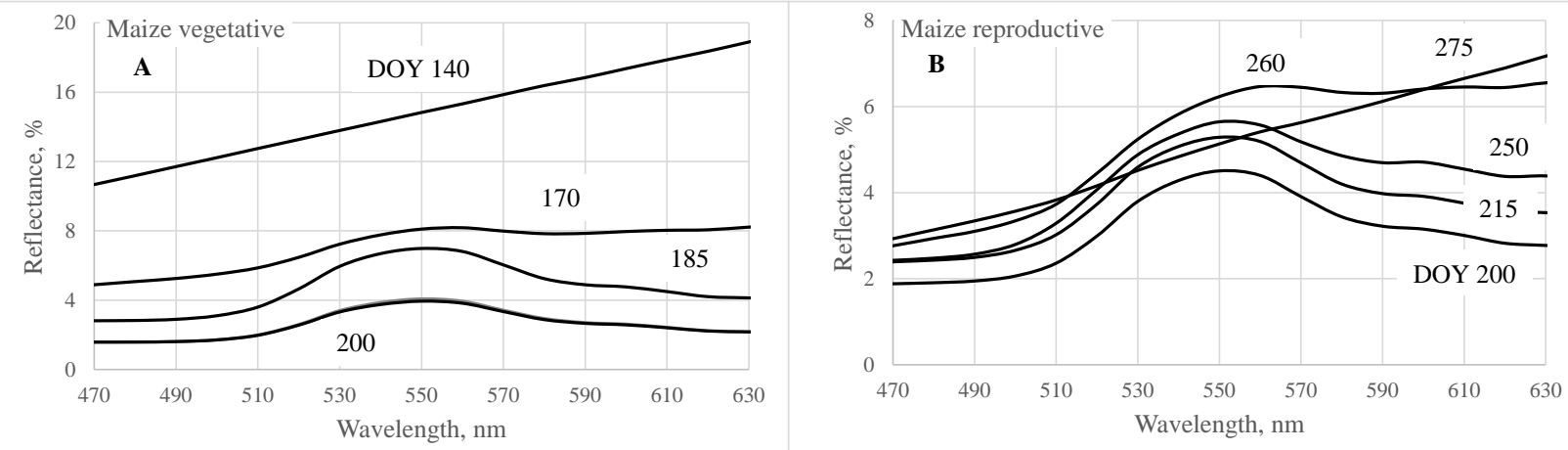

Fig. 2. Canopy reflectance spectra of maize in vegetative $(A)$ and reproductive $(B)$ stages.

In the reproductive stage, when leaf $\mathrm{Chl}$ content decreased but leaf area remained virtually invariant, $\rho 530$ and $\rho 570$ increased almost synchronously in accord with a decrease of foliar Chl content and green LAI (Fig. 2B, DOY 200 through 250). So the PRI numerator ( $\rho 530$ - $\rho 570$ ) 
222 remained virtually invariant while the PRI denominator $(\rho 530+\rho 570)$ increased, decreasing PRI

223 (Figs. 1 and 3). Thus, in contrast to the vegetative stage, in the reproductive stage, the decrease

224 of PRI was almost synchronous with a decrease of green LAI (Fig. 1). In late senescence, when

225 foliar Chl dropped sharply, carotenoids became the primary leaf pigments (Fig. 2B, DOY from

226250 through 270). This restricted the rate of $\rho 530$ increase comparable to that of $\rho 570$ due to a

227 significant absorption by carotenoids at $530 \mathrm{~nm}$ and negligible absorption of Car at $570 \mathrm{~nm}$

228 (Lichtenthaler, 1987). Only at this stage did the numerator of PRI play a significant role in the

229 PRI temporal behavior (Fig. 3).
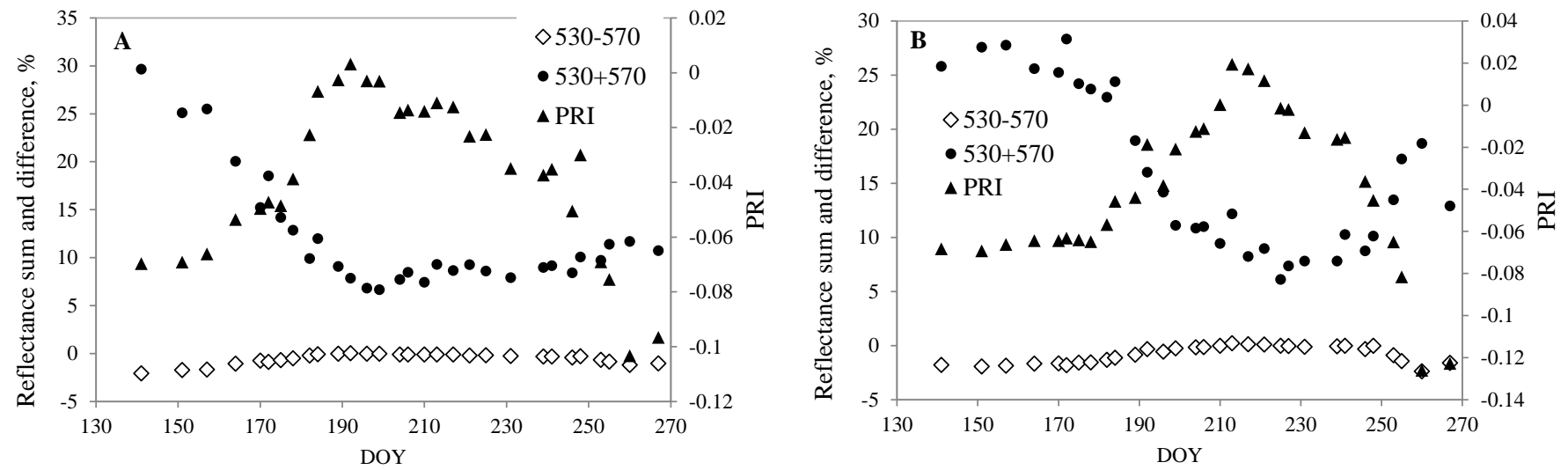

Fig. 3. Temporal behavior of PRI and sum and difference of reflectances at 530 and $570 \mathrm{~nm}$ of

232 maize $(A)$ and soybean $(B)$.

233 The contrasting LAI and PRI behaviors in the vegetative and reproductive stages led to

234 hysteresis when the two were plotted against each other (Fig. 4). While the PRI-LAI

235 relationships were very close, the slope of the PRI increase in the vegetative stage was much 
smaller than the slope of the green LAI increase in the reproductive stage (Figs. 1 and 4).
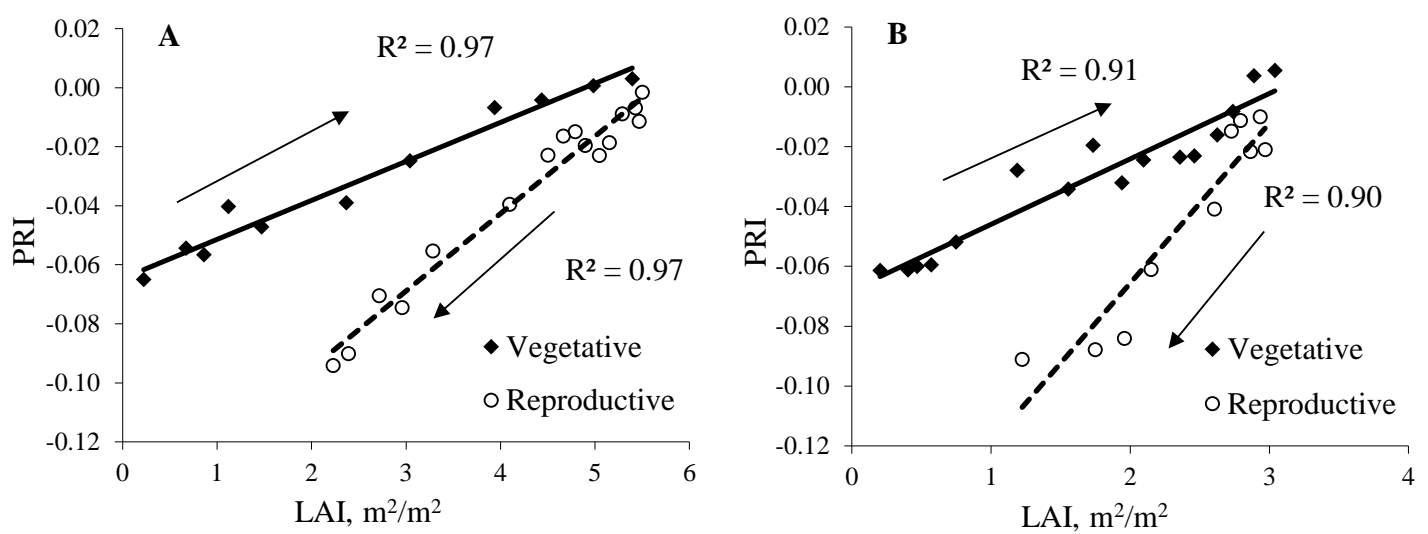

Fig. 4. Relationship between PRI and green LAI in maize (A) and soybean (B).

The main reason for the hysteresis was the high PRI value of soil/residue in the beginning of growing season (Figs. 1, 3, 4). Soil/residue PRI was about -0.06, which corresponded to 40-50\% of its maximal value (0.006), reached at the top of the season in the end of vegetative stage. The minimal value of PRI at the end of the reproductive stage was around - $(0.1-0.12)$, which is much smaller than in the beginning of the season. Thus, in the vegetative stage, the PRI change was between $40-50 \%$ and $100 \%$ of its maximal value while, in the reproductive stage, PRI changed between $100 \%$ and $0 \%$. Hence, the dynamic range of PRI in reproductive stage was $100 \%$ and only $50-60 \%$ in vegetative stage, while the dynamic range of green LAI was $100 \%$ in each stage. This resulted in a strong hysteresis of the PRI-green LAI relationship with the slope of PRI-LAI relationship in vegetative stage 3 -fold smaller than in reproductive stage and senescence (Fig. 4).

This hysteresis may be also in part due to hysteresis in the green LAI vs. stand Chl content relationship (Ciganda et al., 2008; Gitelson et al., 2014). Green LAI has been traditionally determined using a visual subjective attribute of leaf "greenness" (Ciganda et al., 2008; Viña et al., 2011). While a strong linear relationship exists between stand Chl content and green LAI obtained using this subjective procedure (Ciganda et al., 2008; Gitelson et al., 2014), the 
254 relationship leads to hysteresis between stand Chl and green LAI; for the same green LAI, stand

255 Chl content may be much higher in the vegetative stage than in the reproductive stage.

256 The stand $\mathrm{Chl}$ content is an objective, quantitative measure of vegetation vigor that avoids

257 the problem of subjective determination of "greenness". The PRI-stand Chl relationships for

258 maize and soybean were very close (Fig. 5). Although the hysteresis was less than that of PRI-

259 green LAI relationships (Fig. 4), it still was substantial.

260 While PRI-LAI and PRI-Chl relationships were very close, PRI-LUE relationships were

261 weak in both species under different water availability (irrigated and rainfed) - Figs. 6 and 7.

262 Stand Chl content explained more than $90 \%$ variability of PRI, and LUE explained below $0.12 \%$

263 in maize and 9\% in soybean (Fig. 7C).
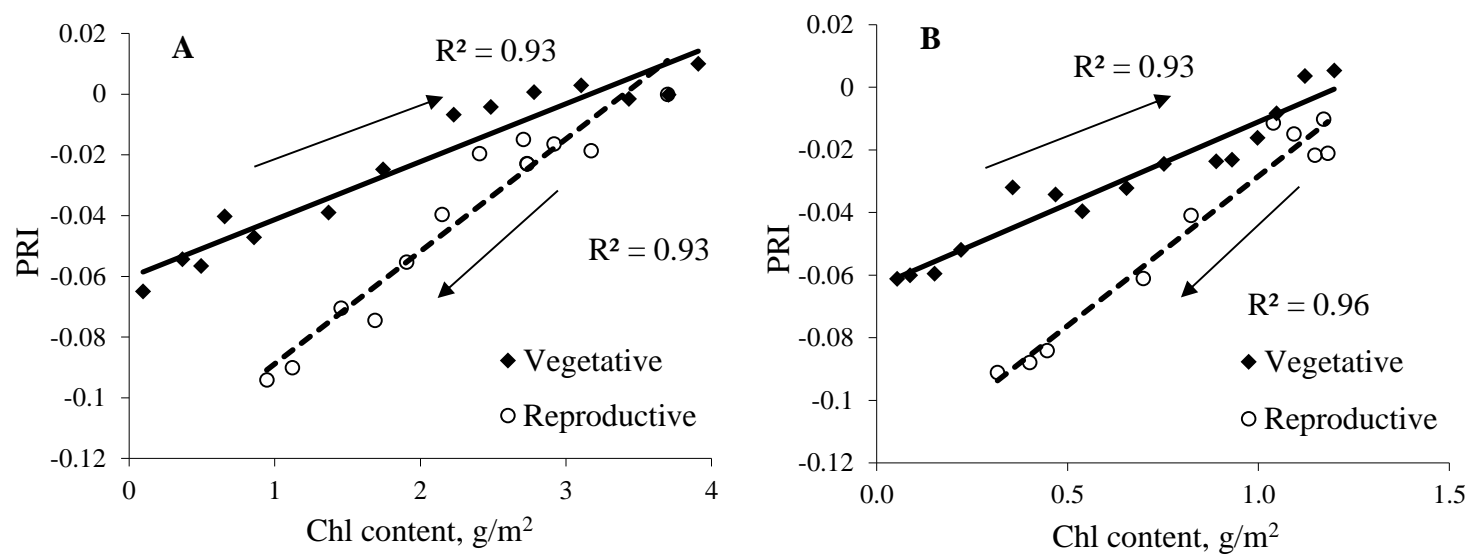

Fig. 5. Relationship between PRI and stand chlorophyll content in maize (A) and soybean B). 

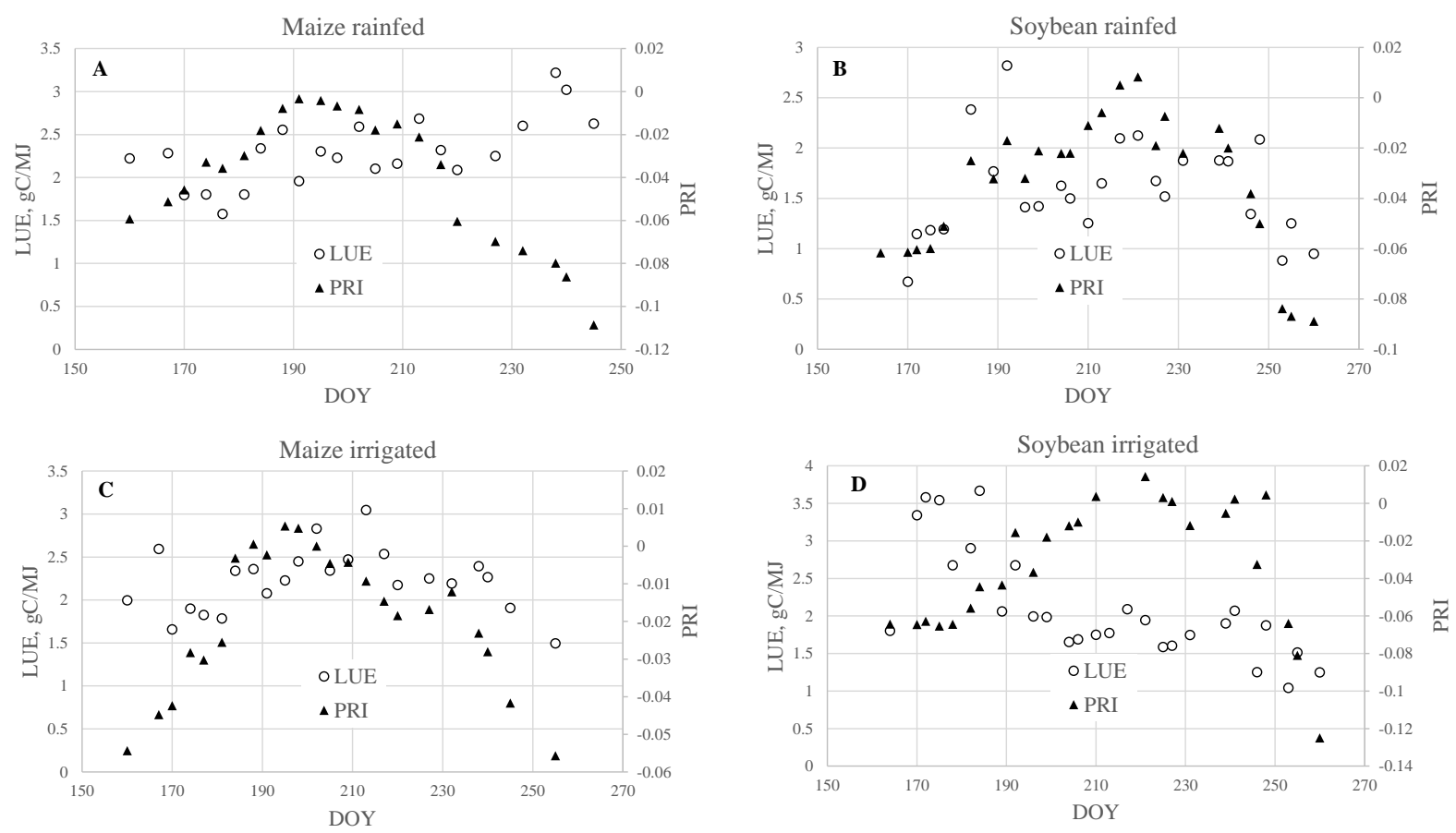

Fig.6. Temporal change in LUE and PRI at irrigated and rainfed maize and soybean sites.
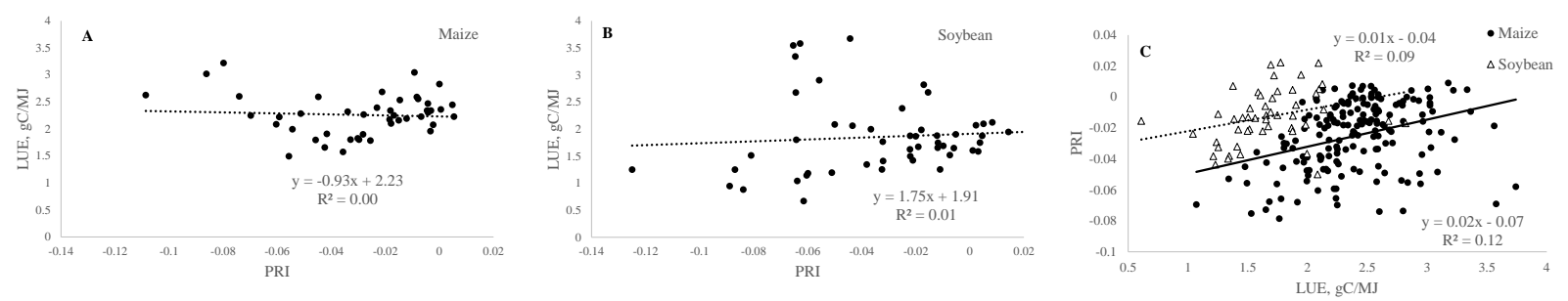

271 Fig. 7. LUE vs. PRI for maize and soybean irrigated and rainfed sites during growing season

2722003 for maize (A), 2002 for soybean (B). PRI vs. LUE for irrigated and rainfed maize and

273 soybean sites in 2001-2005 (C).

274

In this case, over seasonal time scales, PRI emerged more as an index of photosynthetic capacity or activity (Figs. 4 and 5) than LUE (Figs. 6-7) as originally discussed in the early PRI

277 literature focusing on facultative (short-term) PRI variation associated with diurnal xanthophyll cycle activity. However, the slopes of the relationships in different phenological stages, 
279 vegetative and reproductive, were substantially different from each other, indicating that

280 additional factors besides pigment levels alone, specifically the effect of soil/residue background

281 during canopy development in the vegetative stage, were influencing PRI. In the vegetative

282 stage, PRI was largely driven by increasing vegetation cover, green LAI and foliar Chl. In the

283 reproductive and senescence stages, where canopy structure changed relatively little compared to

284 the vegetative stage (Fig. 1), PRI was strongly affected by the foliar Chl decline (Figs. 1 and 8).

285 This decline in PRI without much change in total LAI was especially pronounced in the end of

286 the season at the senescence stage, manifesting the senescence-induced decline of leaf-level

287 pigment pools, which was not as pronounced as in the beginning of reproductive stage in both

288 crops (Fig. 8).
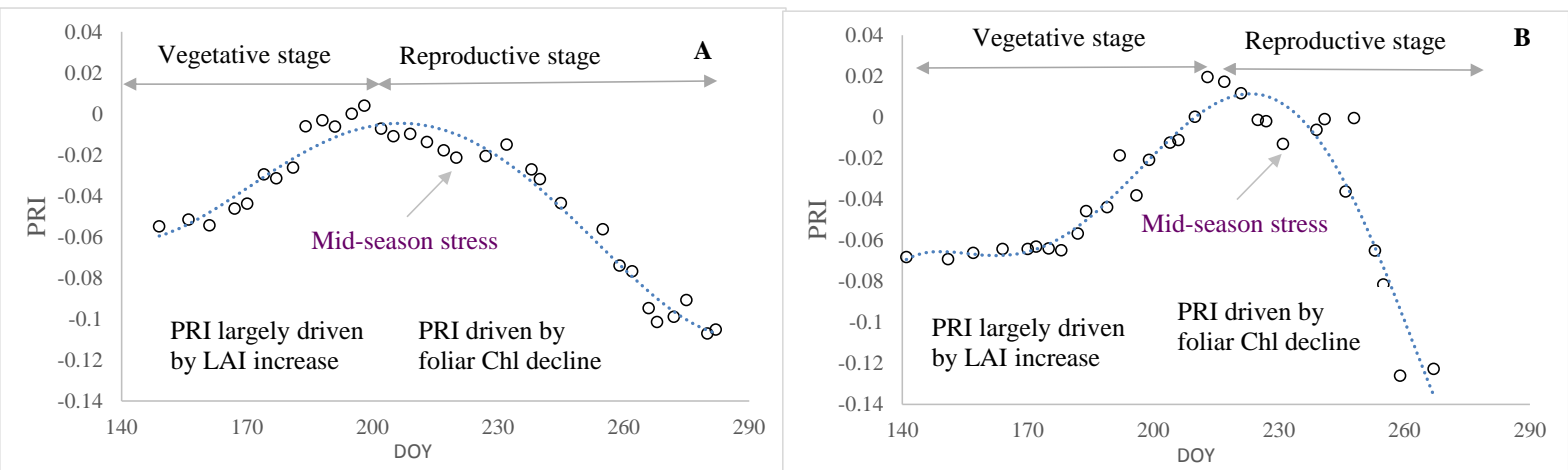

Fig. 8. Seasonal course of PRI for irrigated maize (A) and soybean (B) showing different drivers

of PRI change during the vegetative and reproductive stages. Pronounced minima in the middle

of the season when pigment pools and leaf area were not variable probably indicate crop stress.

In our accompanying paper, we have found that in these annual crops leaf-level PRI is

295 strongly related to the carotenoid-to-chlorophyll ratio, Car/Chl (Gitelson et al., 2016), similar to

296 findings in evergreen vegetation (Stylinski et al., 2002, Sims et al., 2006, Filella et al., 2009,

297 Gamon and Berry, 2012, Wong and Gamon, 2015A and B). To understand whether and how the stand level PRI relates to the Car/Chl ratio in crops, the stand Chl content was estimated by $\mathrm{CI}_{\text {red }}$ 
edge and the stand Car content by the modified carotenoid reflectance index, $\mathrm{mCRI}=\left(\rho_{510^{-1}}-\rho_{\text {red }}\right.$ edge $\left.^{-1}\right) \times \rho_{\text {NIR }}$ (Gitelson et al., 2002, 2006). Then the ratio of these indices was presented as the stand Car/Chl ratio. Both indices have been shown to be accurate measures of $\mathrm{Chl}$ and Car content, respectively (Gitelson et al., 2005, 2006).
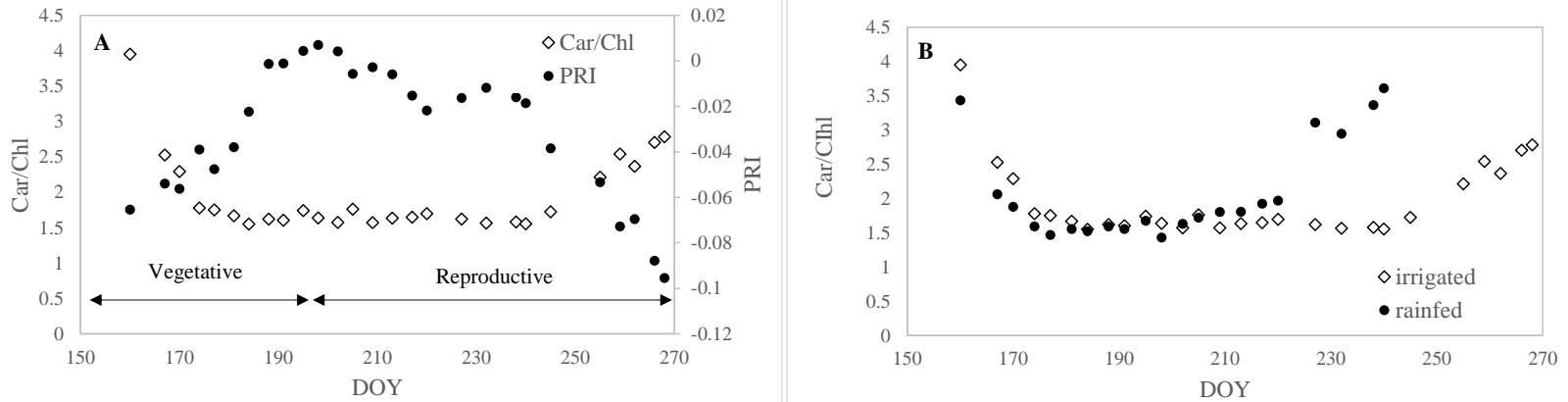

Figure 9. Temporal behavior of PRI and Car/Chl ratio for irrigated maize in arbitrary units (A)

and Car/Chl in irrigated and rainfed maize (B). Car/Chl was calculated as a ratio of modified

carotenoid reflectance index, $m C R I$, to red edge chlorophyll index, $C I_{\text {red edge }}$.

The temporal PRI change was affected by reflectance of soil/residue background that was attenuated as green vegetation fraction increased (Fig. 9A). Maximal PRI value was achieved when crop density was the highest. Along with the decrease of foliar Chl content at the reproductive stage, PRI decreased sharply in the course of senescence. PRI mimicked very closely the temporal profile of the stand Chl content and green LAI (examples in Fig. 1). Thus, the main factor governing seasonal change in stand PRI during senescence was the stand Chl content.

The temporal change pattern in stand-level Car/Chl was very different from that of PRI (Fig. 9A and B). The Car/Chl ratio expectedly decreased in the beginning of the season, illustrating 317 the maturation of photosynthetic apparatus and the deployment of the light-harvesting antenna in the crop leaves, and then remained virtually invariant in the reproductive stage, with a sharp 
319 increase during senescence corresponding to the decrease of Chl content (Fig. 9B). Importantly,

320 the stand Car/Chl was very clearly different between irrigated and rainfed sites. The difference

321 was especially pronounced in the reproductive and senescence stages when Chl sharply

322 decreased in the rainfed crop reflecting a higher degree of stress more affected by water shortage

323 and, thus, Car/Chl increased substantially. Thus, in contrast to PRI at the leaf level, crop stand

324 PRI relates primarily to the stand Chl content and green LAI, and did not relate strongly to the

325 leaf-level Car/Chl ratio, unlike previous leaf-level studies of PRI (e.g., Gitelson et al. 2016).

326 These finding reflected the strong influence of canopy closure and changing vegetation/soil

327 cover on PRI at the stand scale in these annual crops, illustrating the importance of considering

328 spatial and temporal scale as well as vegetation type when using PRI as an indicator of

329 photosynthetic activity.

330

331

332

333

334

335

336

337

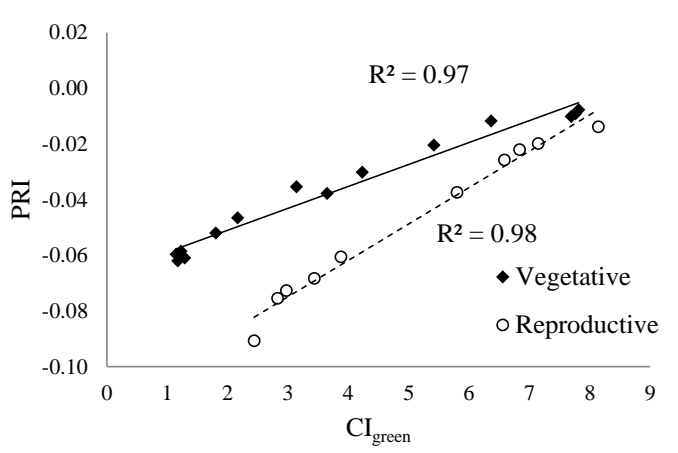

Fig. 10. Relationship between PRI and green chlorophyll index, $C I_{\text {green }}=\left(\rho_{N I R} / \rho_{570}\right)-1$, in maize.

To reveal facultative changes in PRI associated with short-term periods of stress, the original intent of the PRI index (Gamon et al. 1992, Peñuelas et al. 2005, Gamon et al. 1997), the larger background of seasonal change in PRI due to changing canopy structure and constitutive pigment effects must first be considered. To illustrate this, we used the close relationships between the stand $\mathrm{Chl}$ vs. $\mathrm{CI}_{\text {green }}$ (Fig. 10) and subtracted the stand Chl content effect from PRI. The slopes of PRI vs. stand Chl as well as PRI vs. CI relationships were different in vegetative 
and reproductive stages (Fig. 5). So to estimate stand $\mathrm{Chl}$ content over the whole season, we used two equations relating PRI and the stand Chl content, one for the vegetative stage and another for the reproductive and senescence stages. Then, we scaled PRI and the stand Chl content between 0 and 1 and subtracted scaled stand $\mathrm{Chl}$ from scaled stand PRI. The difference, $\mathrm{PRI}_{\mathrm{sc}}-\mathrm{Chl}_{\mathrm{sc}}$, was

342 plotted together with LUE (presented in Gitelson et al., 2015) for rainfed maize (Fig. 11). The

343 variability of residuals was at about $7 \%$, which corresponds well to the expected facultative 344 change in LUE for maize examined in this study (Gitelson et al., 2015) and the temporal 345 behaviors of residuals, $\mathrm{PRI}_{\mathrm{sc}}-\mathrm{Chl}_{\mathrm{sc}}$, and LUE were in agreement (Fig. 11B). The main reason 346 for the wide variation of LUE in the beginning of the season was related to uncertainties of $f_{\mathrm{APAR}}$ 347 measurement at sparse canopy (Gitelson et al., 2015). This method revealed two noticeable dips 348 in PRI and LUE, one around days 170-180, and a second dip between the days 200 and 230.

349 Those were due to dry weather condition and decline in soil moisture in the rainfed maize in 3502003 (Peng et al., 2013; Gitelson et al., 2015). 354 355 356

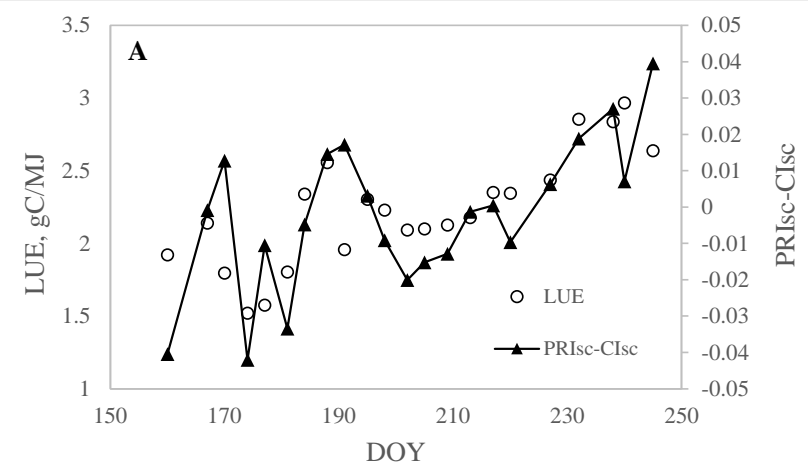

Fig. 11. Temporal behavior of light use efficiency (LUE) and difference between scaled PRI and

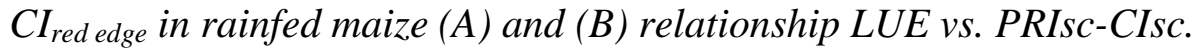

Despite the encouraging result for this particular case, it is premature to say whether the suggested approach, subtraction of stand Chl content from stand PRI, would be able to accurately 
assess LUE using seasonal PRI data and stand Chl-related vegetation indices in all cases. There are several challenges that must be first overcome. The primary challenge is the uncertainty caused by variability in the PRI-Chl relationships, which may be both intraspecific (with variation of canopy architecture) and interspecific. Different slopes of PRI-Chl relationships for vegetative and reproductive stages revealed in this study require accurate remote estimation of

362 the time window when maximal values of either green LAI or stand Chl content appear 363 indicating the changeover of vegetative and reproductive stages. Further, we note that the 364 calculation of LUE depends upon the assumptions made and definitions used (Gitelson and 365 Gamon, 2015). In an attempt to remove any effects of changing green canopy structure on 366 apparent LUE, in this case we based the LUE calculation on radiation absorbed by 367 photosynthetically active "green" vegetation defined as $f_{\text {APARgreen }}=f_{\text {APAR }} \times($ green LAI/total 368 LAI), as described in Hall et al., (1992), Vina and Gitelson, (2005), not total absorbed or incident 369 radiation. Without doing this, a very different seasonal pattern of LUE would result (see 370 comparison in Fig. 4, Gitelson and Gamon, 2015).

371 The hypothesis that LUE can be assessed after correction for the larger seasonal change in 372 PRI due to canopy structure and pigmentation requires very thoughtful testing across a range of 373 species and conditions, with close attention to the issues discussed here. We note that we would 374 not expect all species and vegetation types to have similar PRI responses (Garbulsky et al., 2010, 375 Gamon, 2015). For example, evergreen versus annual species would presumably yield 376 contrasting seasonal patterns of PRI, canopy structure, and photosynthetic activity. In 377 evergreens, large changes in $\mathrm{Car} / \mathrm{Chl}$ occur with the spring activation and winter deactivation of 378 photosynthesis, reflecting a very clear role for constitutive pigment changes in the seasonal PRI 379 signal that can be closely tied to seasonal patterns of photosynthetic activity and LUE (Wong \& 
Gamon, 2015B). Garbulsky et al., (2011) and Gamon, (2015) have suggested that the PRI-

381

photosynthesis (or LUE) relationship would vary for different types of vegetation. They hypothesized that for annual plants (e.g., crops) the changing canopy structure (e.g. LAI or canopy cover) would be a strong driver of the PRI signal. This has not been fully tested yet.

Notably, the changes in PRI indeed reflecting changes in LUE modulated by the xanthophyll cycle are relatively small in magnitude and occur on a much faster (minute to hours) time scale (Gamon et al., 1992; Solovchenko et al., 2010) than the changes associated with seasonally changing canopy structure and pigment pools (Gamon and Berry, 2012; Wong and Gamon, 2015A and B). LUE-related PRI changes can be tightly linked not only with the Car/Chl ratio per se but with (dis)engagement of energy-dependent photoprotective mechanisms also apparent as non-photochemical quenching of Chl fluorescence (Horton, 2014). In view of these circumstances, interpretation and comparison of PRI should be done with caution, particularly when made across species or growth conditions. It should also take into account the plant ontogenetic stage and stress acclimation state, very much the same as for Chl-fluorescence-based LUE estimation, representing an alternative method of estimating LUE (Maxwell, Johnston, 2000) that can be tightly linked to PRI (Gamon et al., 1997; Solovchenko et al., 2010).

\section{Conclusions}

Analysis of seasonal changes in the stand chlorophyll content and green leaf area index in two crops, maize and soybean, lead to the following conclusions.

- In both crops, maize and soybean, PRI related very closely to stand Chl content $\left(\mathrm{R}^{2}>0.93\right)$ and green LAI $\left(\mathrm{R}^{2}>0.9\right)$. PRI was not clearly related to LUE of photosynthetically active vegetation that explained below $12 \%$ of PRI variation. Thus, canopy structure exerted a dominant influence at both vegetative and reproductive stages. 
- The dynamic range of PRI at vegetative stage was restricted by high PRI value of soil/residue and, the slopes of PRI-LAI relationships were significantly different for vegetative and reproductive stages. At the reproductive stage, PRI was about 3-fold more sensitive to $\mathrm{Chl}$ content and green LAI than at vegetative stage.

- Unlike leaf-level responses, PRI was less clearly related to the stand level Car/Chl ratio in crops, likely due to the confounding effect of changing canopy structure.

- PRI was closely related to green and red edge chlorophyll indices that were found to be accurate measures of green LAI and stand Chl content. The strong relationship between PRI and stand $\mathrm{Chl}$ content/chlorophyll indices over a growing cycle allowed us to subtract the stand Chl effect from measured PRI to reveal the facultative PRI change related to short periods of stress.

- For accurate subtraction of Chl effect from long-term PRI records, thoughtful study of uncertainties related to "natural" variation of PRI-stand Chl relationships, and stand Chl estimation for different varieties of the same species as well as between different species is required. A better understanding of these relationships and their variation for different types of vegetation is a key for understanding the PRI-LUE relationship.

- In light of other recent studies, these findings have important implications for attempts to monitor photosynthetic activity from satellite platforms, and indicate careful consideration of sampling context (including vegetation type, temporal scale, and spatial scale) and operational definitions (e.g. LUE formulation) is needed when using PRI remotely.

\section{Acknowledgements}


This research was supported by Lady Davis and Marie Curie International Incoming

426 Fellowship to AG, and partially supported by the NASA NACP program and the U.S.

427 Department of Energy. We sincerely appreciate the support and use of facilities and equipment

428 provided by the Center for Advanced Land Management Information Technologies (CALMIT)

429 and data from the Carbon Sequestration Program, both at the University of Nebraska-Lincoln.

430 AS acknowledges the financial support of Russian Scientific Foundation (grant \# 14-50-00029).

431 We are very thankful to RSE Associate Editor Pablo J. J. Zarco-Tejada and three anonymous

432 reviewers for their very constructive and helpful reviews.

433

434 References

435 Barton, C. V. M., and North, P. R. J. (2001). Remote sensing of canopy light use efficiency using 436 the photochemical reflectance index - Model and sensitivity analysis, Remote Sensing of 437 Environment, 78, 264-273, doi:10.1016/s0034-4257(01)00224-3.

438 Bilger, W., Björkman, O., \& Thayer, S. S. (1989) Light-induced spectral absorbance changes in 439 relation to photosynthesis and the epoxidation state of xanthophyll cycle components in $440 \quad$ cotton leaves. Plant Physiology, 91, 542-551.

441 Ciganda, V., Gitelson, A.A. and Schepers, J. (2008). Vertical Profile and Temporal Variation of 442 Chlorophyll in Maize Canopy: Quantitative “Crop Vigor” Indicator by Means of

$443 \quad$ Reflectance-Based Techniques, Agronomy Journal, 100, 1409-1417.

444 doi:10.2134/agronj2007.0322

445 Ciganda, V., Gitelson, A.A. and Schepers, J. (2009). Non-destructive determination of maize leaf $446 \quad$ and canopy chlorophyll content. Journal of Plant Physiology, 166,157-167. 
447 Drolet, G.G., Huemmrich, K.F., Hall, F.G., Middleton, E.M., Black, T.A., Barr, A.G., AND

448 Margolis, H.A. (2005). A MODIS-derived photochemical reflectance index to detect inter-

449 annual variations in the photosynthetic light-use efficiency of a boreal deciduous forest.

$450 \quad$ Remote Sensing of Environment, 98, 212 - 224.

451 Filella, I., Porcar-Castell, A., Munne-Bosch, S., Back, J., Garbulsky, M. F., and Peñuelas, J.

452 (2009). PRI assessment of long-term changes in carotenoids/chlorophyll ratio and short-term

453 changes in de-epoxidation state of the xanthophyll cycle, International Journal of Remote

$454 \quad$ Sensing, 30, 4443-4455, doi: 10.1080/01431160802575661.

455 Gamon, J.A. (2015). Optical sampling of the flux tower footprint. Biogeosciences, 12, 4509-

456 4523. doi:10.5194/bg-12-4509-2015

457 Gamon, J.A., Berry, J.A. (2012). Facultative and constitutive pigment effects on the 458 Photochemical Reflectance Index (PRI) in sun and shade conifer needles. Israel Journal of 459 Plant Sciences, 60, 85-95. DOI: 10.1560/IJPS.60.1-2.85.

460 Gamon, J.A., Filella, I., Peñuelas, J. (1993). The dynamic 531-nanometer $\Delta$ reflectance signal: a 461 survey of twenty angiosperm species. Yamamoto HY, Smith CM (Eds). Photosynthetic 462 463 Responses to the Environment. American Society of Plant Physiologists, Rockville. pp. 172-

466 Gamon, J.A., Field, C.B., Fredeen, A.L., Thayer, S. (2001). Assessing photosynthetic 467 downregulation in sunflower stands with an optically-based model. Photosynthesis Research, $468 \quad 67,113-125$. 
Gamon, J.A., Serrano, L., and Surfus, J. (1997). The photochemical reflectance index: an optical indicator of photosynthetic radiation use efficiency across species, functional types, and nutrient levels. Oecologia 112(4), 492-501.

Gamon, J.A., Surfus, J.S. (1999). Assessing leaf pigment content and activity with a reflectometer. New Phytologist, 143, 105-117.

Gamon, J.A., Roberts, D.A., Green, R.O. (1995). Evaluation of the photochemical reflectance index in AVIRIS imagery. In: Green RO (Ed), Proceedings of the Fifth Annual JPL Airborne Earth Science Workshop, Pasadena, 23-26 January 1995. JPL Publication 95-1, 55-58.

Gamon, J.A., Qiu, H-L. (1999). Ecological applications of remote sensing at multiple scales. pp. 805-846 In: Pugnaire FI, Valladares F (Eds), Handbook of Functional Plant Ecology. Marcel Dekker, Inc. New York.

Garbulsky, M. F., Peñuelas, J., Gamon, J., Inoue, Y., and Filella, I. (2011). The photochemical reflectance index (PRI) and the remote sensing of leaf, canopy and ecosystem radiation use efficiencies: A review and meta-analysis, Remote Sensing of Environment, 115, 281-297, doi:10.1016/j.rse.2010.08.023, 2011.

Garrity, S. R., Eitel, J. U. H., and Vierling, L. A. (2011). Disentangling the relationships between plant pigments and the photochemical reflectance index reveals a new approach for remote estimation of carotenoid content, Remote Sensing of Environment, 115, 628-635, doi:10.1016/j.rse.2010.10.007.

Gitelson A.A., Gamon, J.A. (2015). The need for a common basis for defining light-use efficiency: implications for productivity estimation. Remote Sensing of Environment 156, 196-201. 
491 Gitelson, A.A., Peng, Y., Arkebauer, T.J. Suyker, A.E. (2015). Productivity, absorbed

492 photosynthetically active radiation, and light use efficiency in crops: Implications for remote

493 sensing of crop primary production, Journal of Plant Physiology, 177, 100-109,

$494 \quad$ http://dx.doi.org/10.1016/j.jplph.2014.12.015

495 Gitelson, A. A., Peng, Y. Huemmrich, K. F. (2014). Relationship between fraction of radiation

496 absorbed by photosynthesizing maize and soybean canopies and NDVI from remotely sensed

497 data taken at close range and from MODIS $250 \mathrm{~m}$ resolution data, Remote Sensing of

$498 \quad$ Environment, 147, 108-120.

499 Gitelson, A.A., Gritz, U. and Merzlyak M.N. (2003). Relationships between leaf chlorophyll

500 content and spectral reflectance and algorithms for non-destructive chlorophyll assessment in

501 higher plant leaves. Journal of Plant Physiology, 160(3), 271-282.

502 Gitelson, A.A., Viña, A., Rundquist, D.C., Ciganda, V., Arkebauer, T.J. (2005). Remote

503 Estimation of Canopy Chlorophyll Content in Crops, Geophysical Research Letters, 32,

$504 \quad$ L08403, doi:10.1029/2005GL022688

505 Gitelson, A. A., Keydan, G. P. and Merzlyak, M. N. (2006). Three-band model for noninvasive

506 estimation of chlorophyll, carotenoids, and anthocyanin contents in higher plant leaves,

507 Geophysical Research Letters, 33, L11402, doi:10.1029/2006GL026457.

508 Gitelson, A.A., Gamon, J.A. and Solovchenko. (2016). Multiple drivers of seasonal change in

509 PRI: Implications for photosynthesis. 1. Leaf level. Submitted to Remote Sensing of

510 Environment.

511 Goerner A, Reichstein M, Tomelleri E, Hanan N, Rambal S, Papale D, Dragoni D, Schmullius C.

512 (2011). Remote sensing of ecosystem light use efficiency with MODIS-based PRI.

513 Biogeosciences, 8, 189-202. 
514 Goward, S, N., Huemmrich, K.F. (1992). Vegetation canopy PAR absorptance and the

515 normalized difference vegetation index: An assessment using the SAIL model. Remote Sens

$516 \quad$ Environ. 39, $119-40$.

517 Hall, F. G., K. F. Huemmrich, S. J. Goetz, P. J. Sellers, and J. E. Nickeson (1992), Satellite

518 remote sensing of surface energy balance: Success, failures and unresolved issues in FIFE,

$519 \quad$ Journal of Geophysical Research, 97, 19,061 - 19,089.

520 Horton, P. (2014). Developments in research on non-photochemical fluorescence quenching:

521 emergence of key ideas, theories and experimental approaches. In B. Demmig-Adams, G.

522 Garab, W. Adams III, and Govindjee (Eds.), Non-photochemical quenching and energy

523 dissipation in plants, algae and cyanobacteria (pp. 73-95). Dordrecht: Springer Netherlands.

524 Lichtenthaler, H.K. (1987) Chlorophyll and carotenoids: Pigments of photosynthetic

525 biomembranes. Meth Enzym 148, 331-382.

526 Nichol, C.J, Lloyd, J, Shibistova, O., Arneth, A., Röser, C., Knohl, A., Matsubara ,S., Grace, J.

527 (2002). Remote sensing of photosynthetic light-use efficiency of a Siberian boreal forest.

$528 \quad$ Tellus 54B, 677-687.

529 Maxwell, K., \& Johnson, G. (2000). Chlorophyll fluorescence-a practical guide. Journal of

530 Experimental Botany, 51, 659-668.

531 Monteith, J. L. (1972), Solar radiation and productivity in tropical ecosystems, J. Appl. Ecol., 9, $532 \quad 744-766$.

533 Monteith, J.L., Moss, C. J. (1977). Climate and the Efficiency of Crop Production in Britain [and 534 Discussion], Philosophical Transactions of the Royal Society B, 281(9), 277-294. DOI:

$535 \quad 10.1098 /$ rstb. 1977.0140 
Nguy-Robertson, A. L., Y. Peng, AA. Gitelson, T. J. Arkebauer, A. Pimstein, I. Herrmann, A. Karnieli, D. C. Rundquist, D. J. Bonfil. (2014). Estimating green LAI in four crops: Potential of determining optimal spectral bands for a universal algorithm, Agricultural and Forest Meteorology, 192-193: 140-148.

Nguy-Robertson, A.L., A.A. Gitelson, Y. Peng, A. Viña, T.J. Arkebauer, Rundquist, D.C. (2012). Green leaf area index estimation in maize and soybean: Combining vegetation indices to achieve maximal sensitivity, Agronomy Journal, 104, 1336-347.

Peng, Y., Gitelson, A.A., T Sakamoto. (2013). Remote estimation of gross primary productivity in crops using MODIS 250 m data, Remote Sensing of Environment, 128, 186-196.

Peñuelas, J., Filella, I., Gamon, J.A. (1995). Assessment of photosynthetic radiation-use efficiency with spectral reflectance, New Phytologist 131, 291-296.

Rahman A. F., V. D. Cordova, J. A. Gamon, H. P. Schmid, D. A. Sims (2004), Potential of MODIS ocean bands for estimating $\mathrm{CO} 2$ flux from terrestrial vegetation: A novel approach, Geophysical Research Letters, 31, L10503, doi:10.1029/2004GL019778

Sims, D.A., Gamon, J.A. (2002). Relationships between leaf pigment content and spectral reflectance across a wide range of species, leaf structures and developmental stages. Remote Sensing of Environment 81, 337-354.

Solovchenko, A. (2010). Photoprotection in plants: optical screening-based mechanisms. Heidelberg, New York: Springer.

Stylinski, C.D., Gamon, J.A., and Oechel, W.C. (2002). Seasonal patterns of reflectance indices, carotenoid pigments and photosynthesis of evergreen chaparral species. Oecologia, 131, 366374. 
Verma, S.B., Dobermann, A., Cassman, K.G., Walters, D.T., Johannes M. Knops, J.M., Arkebauer, T.J., Suyker, A.E., Burba, G.G., Amos, B., Yang, H., Ginting, D., Hubbard K.G., Gitelson, A.A., Walter-Shea, E.A. (2005) Annual carbon dioxide exchange in irrigated and rainfed maize-based agroecosystems, Agricultural and Forest Meteorology, 131, 77-96.

Viña, A. and Gitelson, A. A. (2005). New developments in the remote estimation of the fraction of absorbed photosynthetically active radiation in crops, Geophysical Research Letters, 32, L17403, doi:10.1029/2005GL023647.

Viña, A., Gitelson, A.A., Nguy-Robertson A. L., Peng, Y. (2011). Comparison of different vegetation indices for the remote assessment of green leaf area index of crops, Remote Sensing of Environment, 115, 3468-3478, doi:10.1016/j.rse.2011.08.010.

Wong, C.Y.S., Gamon, J.A. (2015A). Three causes of variation in the Photochemical Reflectance Index (PRI) in evergreen conifers. New Phytologist, 206, 187-195, doi:

$$
\text { 10.1111/nph.13159 }
$$

Wong, C.Y.S., Gamon, J.A. (2015B). The Photochemical Reflectance Index (PRI) provides an optical indicator of spring photosynthetic activation in conifers. New Phytologist, 206, 196208, doi: 10.1111/nph.13251

Xu, L., Baldocchi, D.D. (2003). Seasonal trends in photosynthetic parameters and stomatal conductance of blue oak (Quercusdouglasii) under prolonged summer drought and high temperature. Tree Physiol, 23(13), 865-77.

\section{Figure Captions}

Figure 1. Temporal behavior of scaled (between 0 and 1) green LAI and PRI of maize (A) and soybean $(\mathrm{B})$. 
581 Figure 2. Canopy reflectance spectra of maize in vegetative (A) and reproductive (B) stages.

582 Figure 3. Temporal behavior of PRI and sum and difference of reflectances at 530 and $570 \mathrm{~nm}$ of 583 maize (A) and soybean (B).

584 Figure 4. Relationship between PRI and green LAI in maize (A) and soybean (B).

585 Figure 5. Relationship between PRI and stand chlorophyll content in maize (A) and soybean B).

586 Figure 7. LUE vs. PRI for maize and soybean irrigated and rainfed sites during growing season

5872003 for maize (A), 2002 for soybean (B). PRI vs. LUE for irrigated and rainfed maize and

588 Figure 8. Seasonal course of PRI for irrigated maize (A) and soybean (B) showing different

589 drivers of PRI change during the vegetative and reproductive stages. Pronounced minima in the

590 middle of the season when pigment pools and leaf area were not variable probably indicate crop

591 stress.

592 Figure 9. Temporal behavior of PRI and Car/Chl ratio for irrigated maize in arbitrary units (A)

593 and $\mathrm{Car} / \mathrm{Chl}$ in irrigated and rainfed maize (B). Car/Chl was calculated as a ratio of modified

594 carotenoid reflectance index, mCRI, to red edge chlorophyll index, CIred edge.

595 Figure 10. Relationship between PRI and green chlorophyll index, CIgreen $=(\square$ NIR/ $\square 570)-1$, in

596 maize.

597 Figure 11. Temporal behavior of light use efficiency (LUE) and difference between scaled PRI 598 and $\mathrm{CI}_{\text {red edge }}$ in rainfed maize (A) and (B) relationship LUE vs. PRIsc-CIsc. 
Figure $1 \mathrm{~A}$

Click here to download Figure: Fig1a.pdf

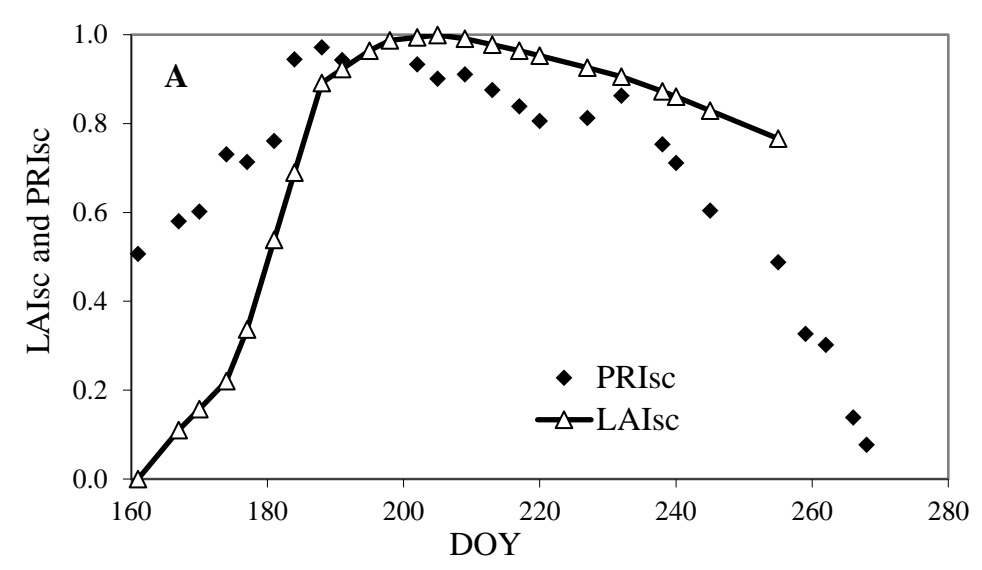


Figure 1b

Click here to download Figure: Fig1b.pdf

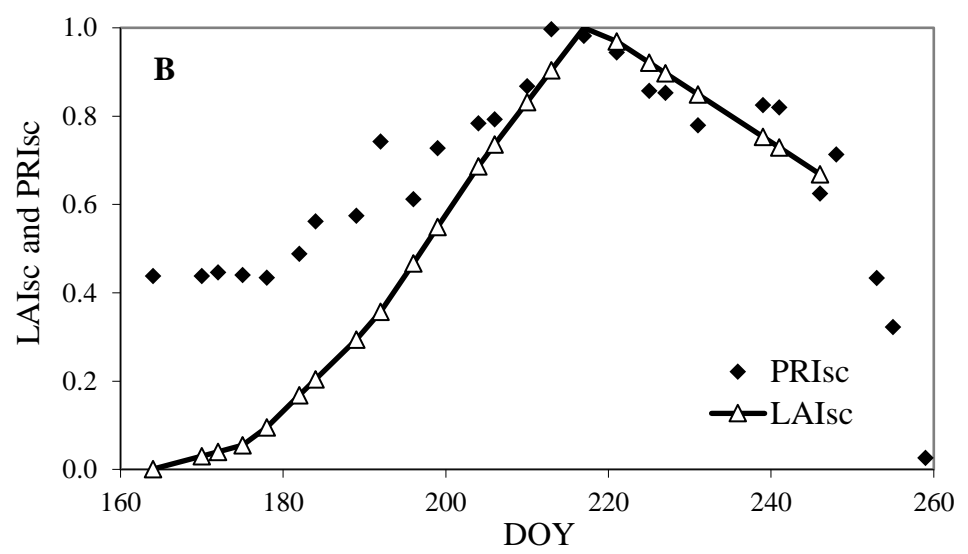


Figure 2A

Click here to download Figure: Fig2a.pdf

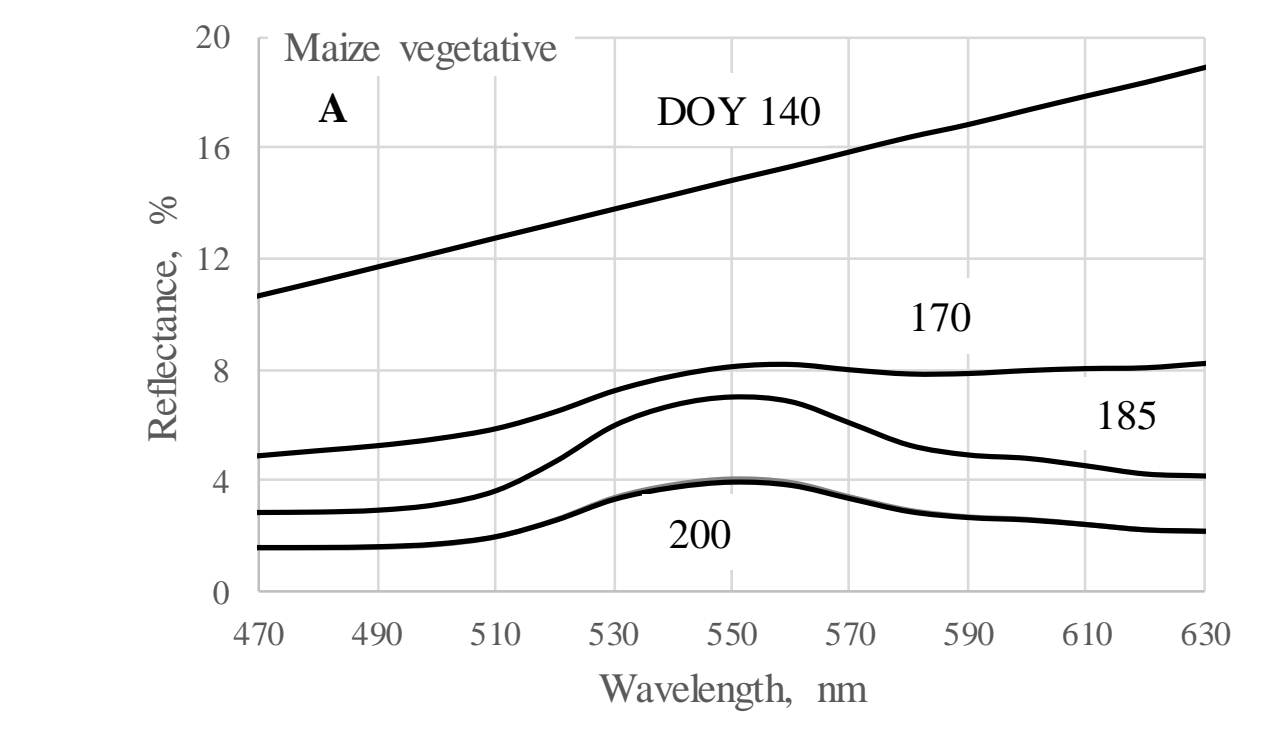

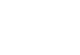

Wavelon,

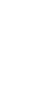

.

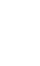

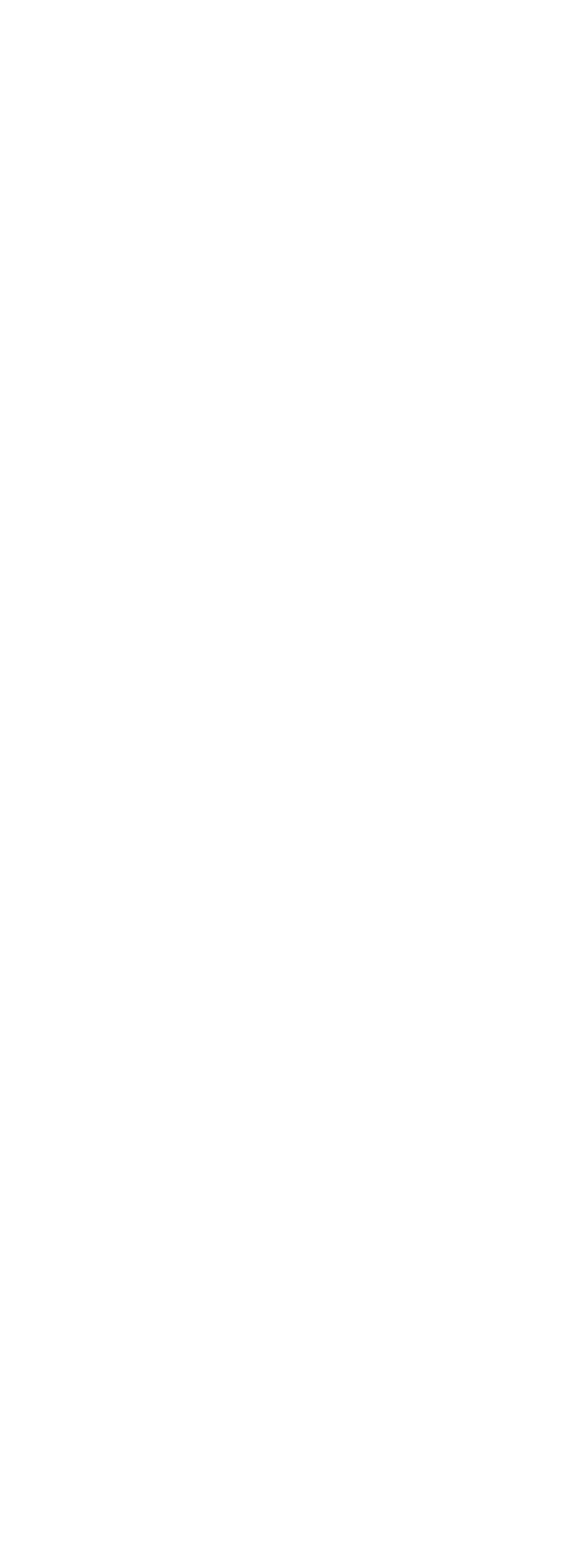
(1) 

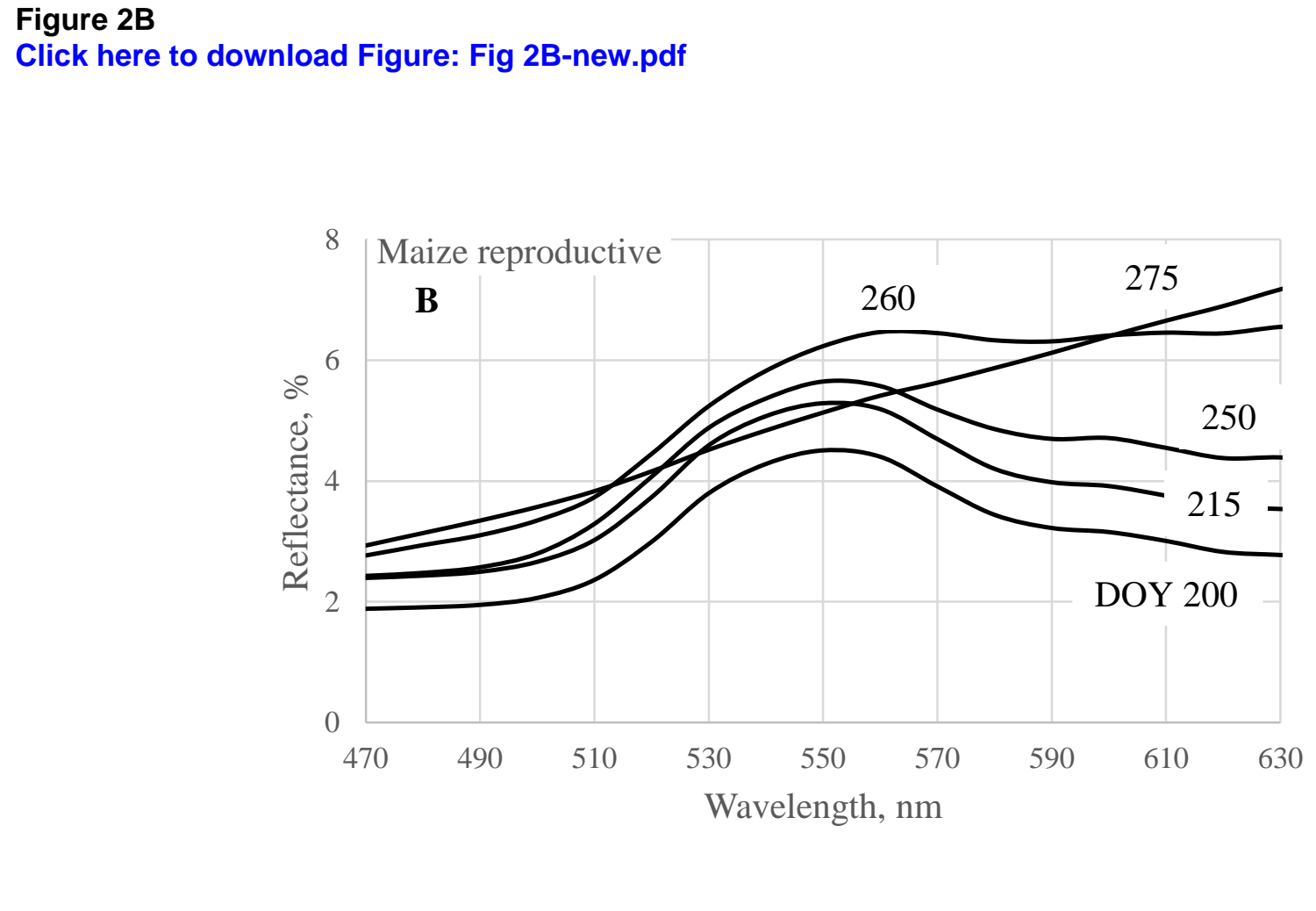

Figure 2B
Click here to download Figure: Fig 2B-new.pdf

(2)

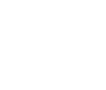

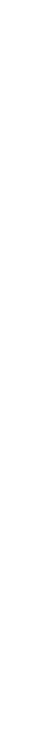
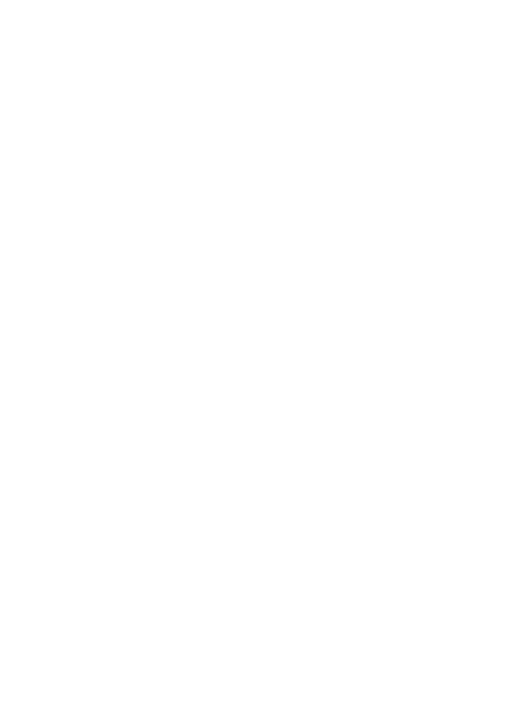
Wavent

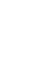

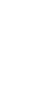


Figure $3 \mathrm{~A}$

Click here to download Figure: Fig3a.pdf

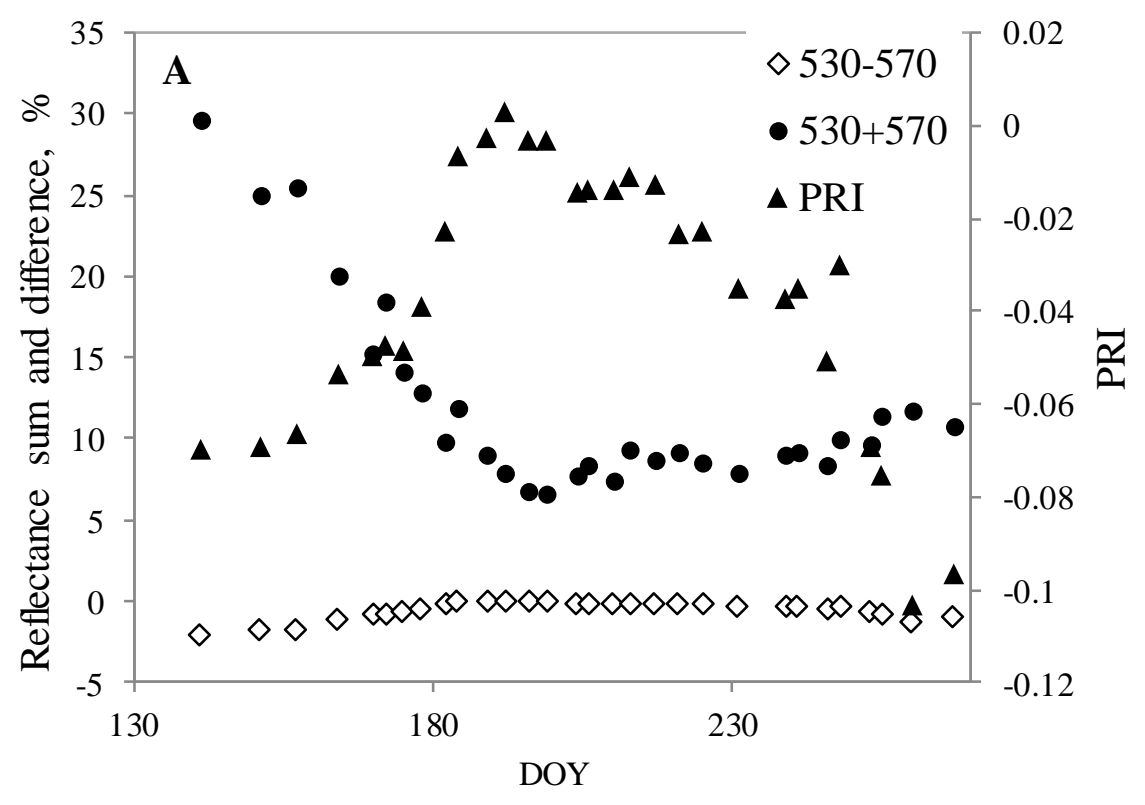


Figure 3B

Click here to download Figure: Fig3b.pdf

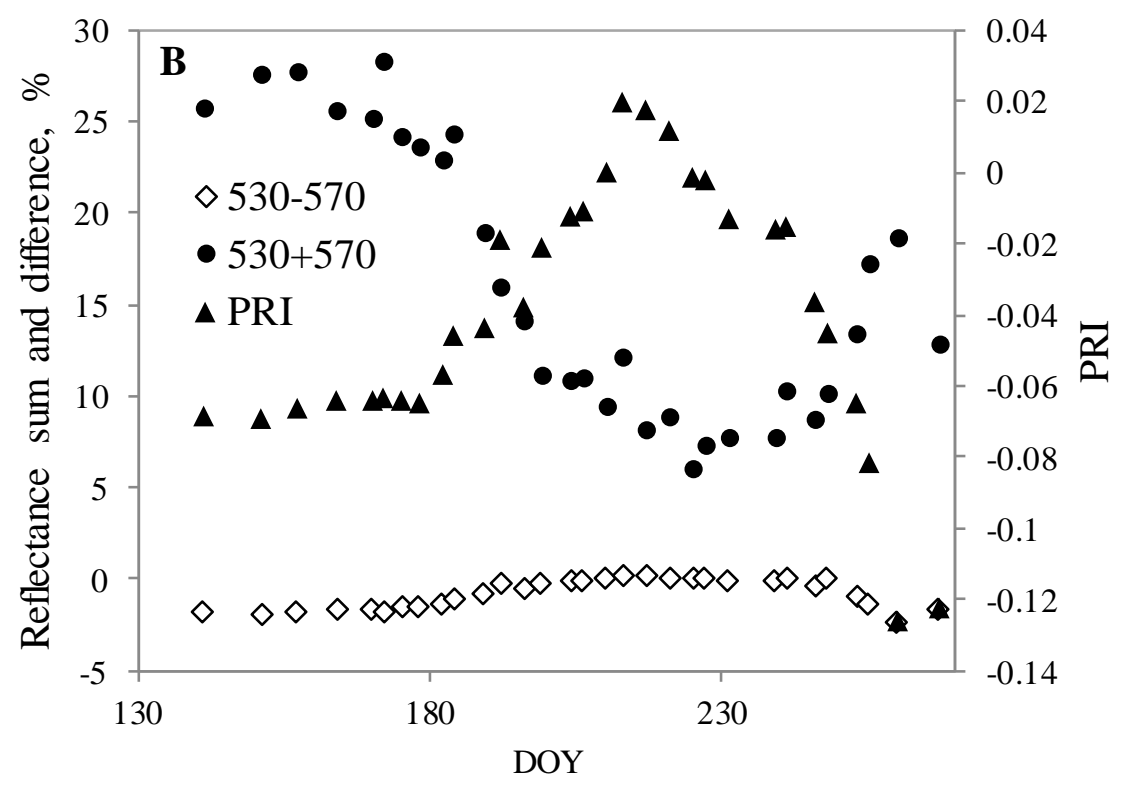


Click here to download Figure: Fig4a.pdf

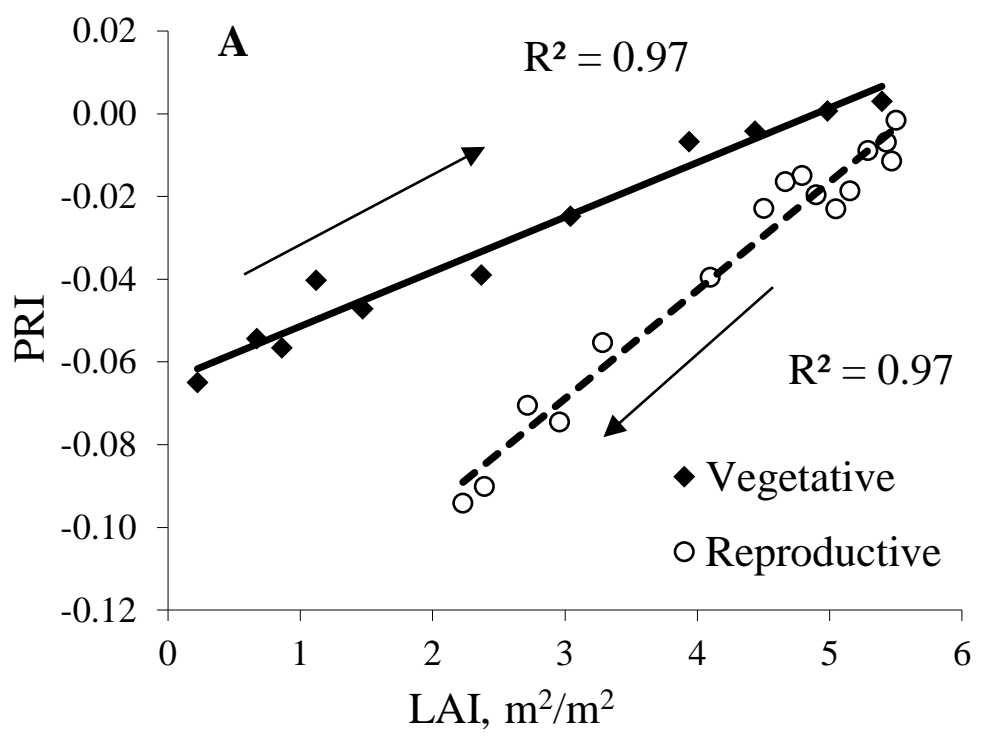


Click here to download Figure: Fig4b.pdf

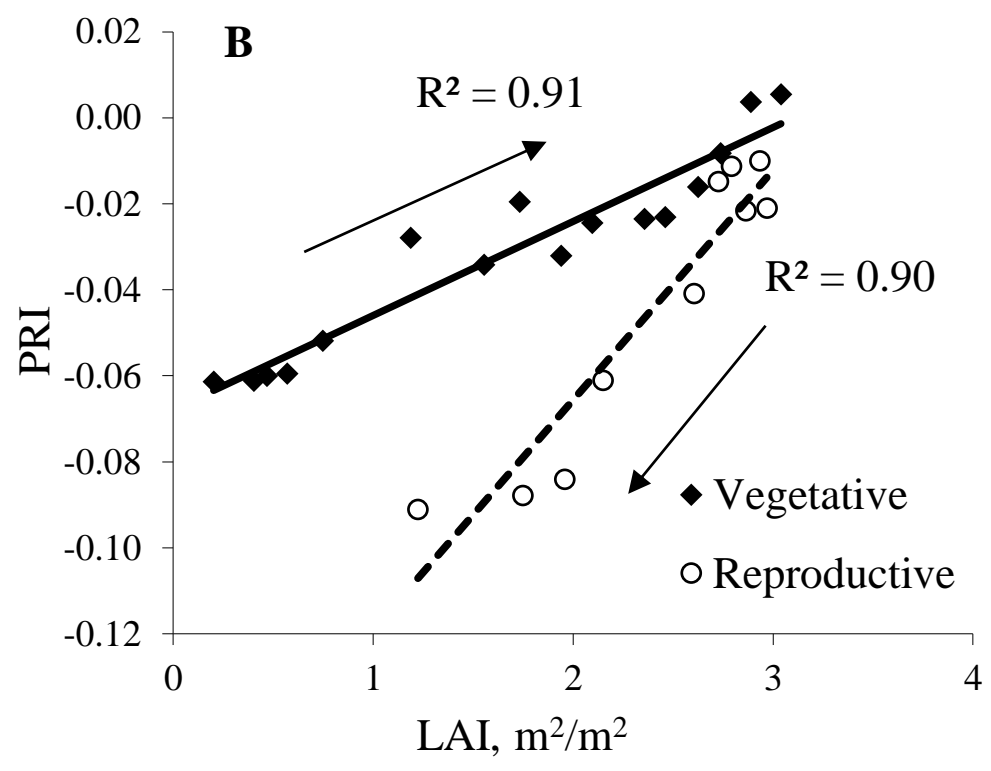




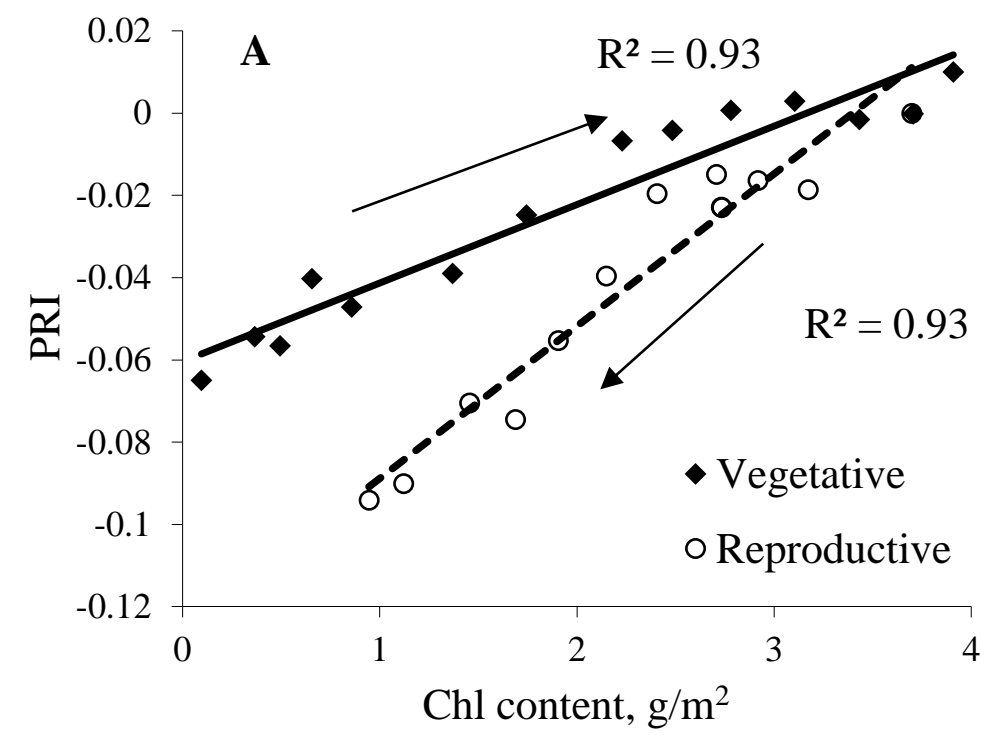


Click here to download Figure: Fig5b.pdf

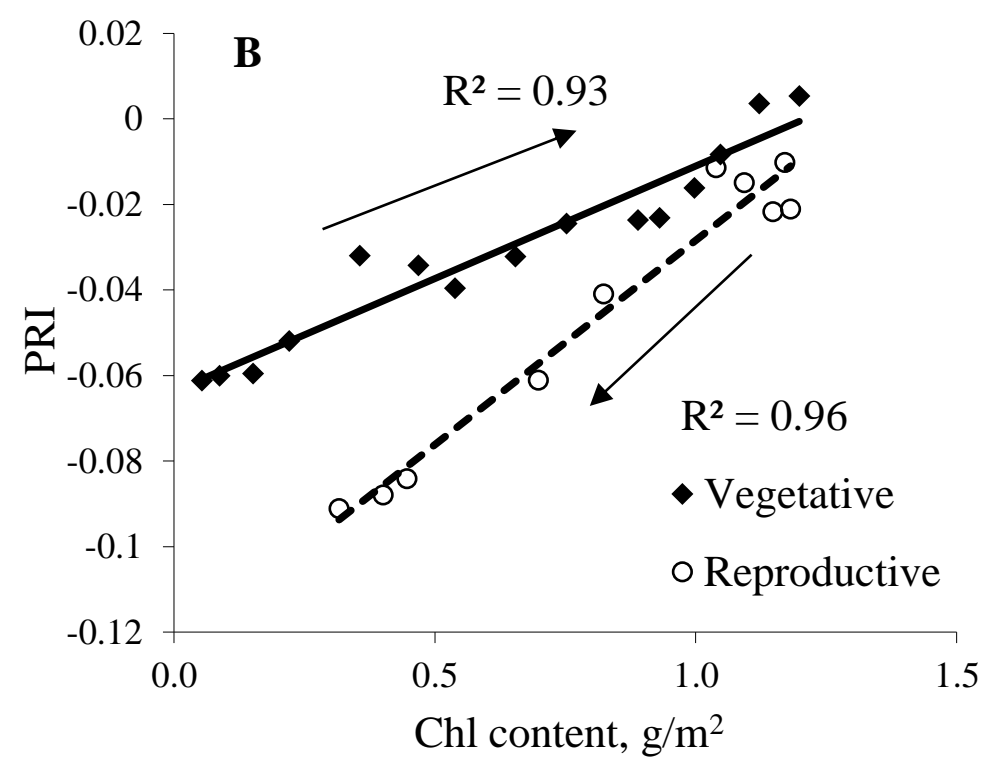


Figure 6A

Click here to download Figure: Fig6a.pdf

Maize rainfed

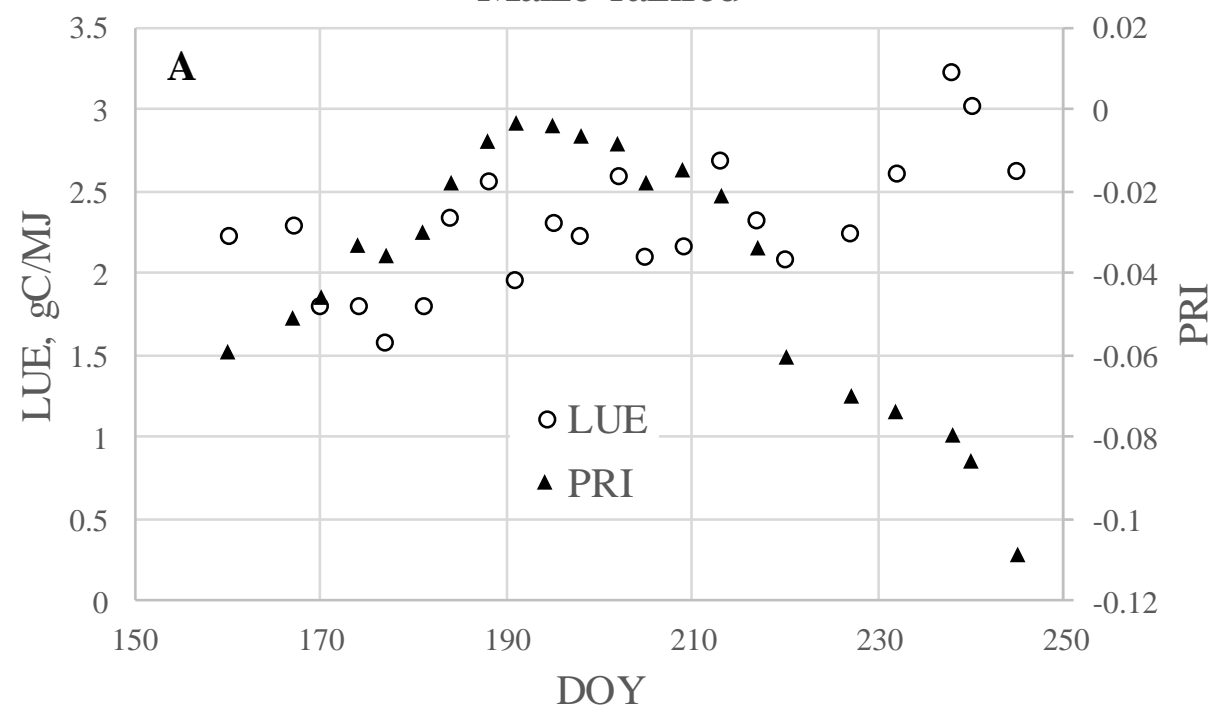




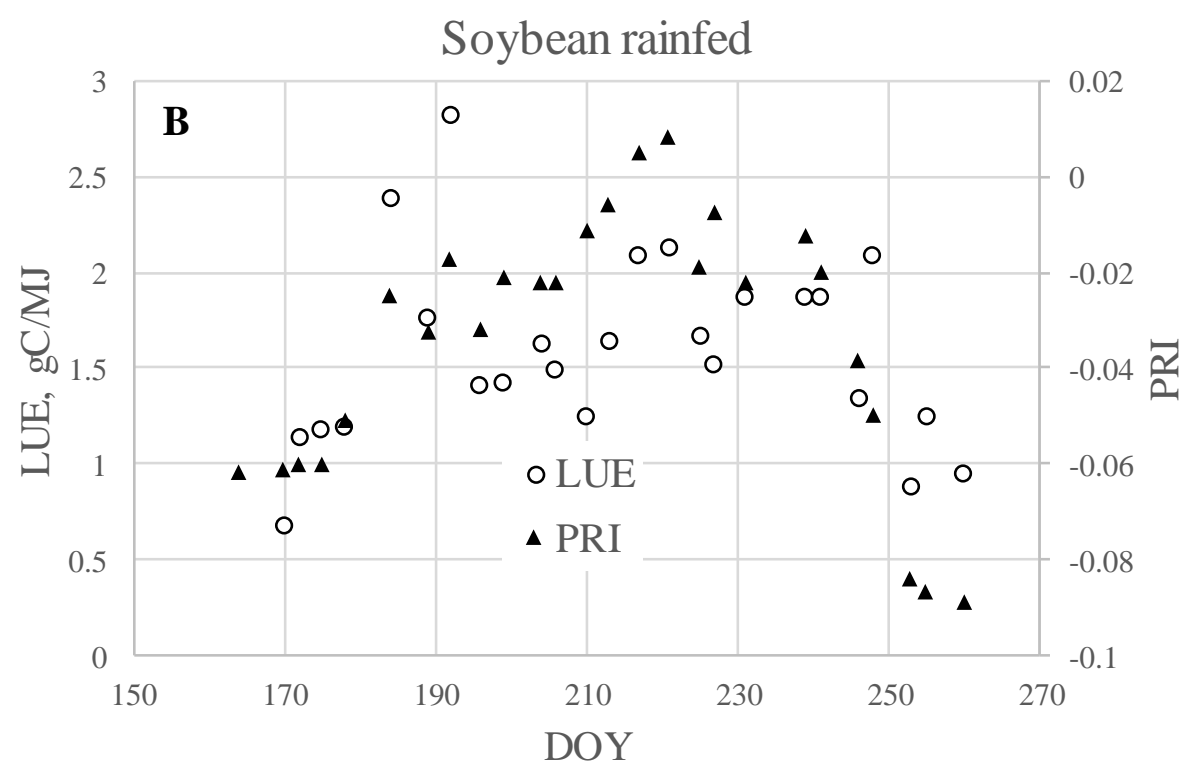


Figure 6C
Click here

Maize irrigated

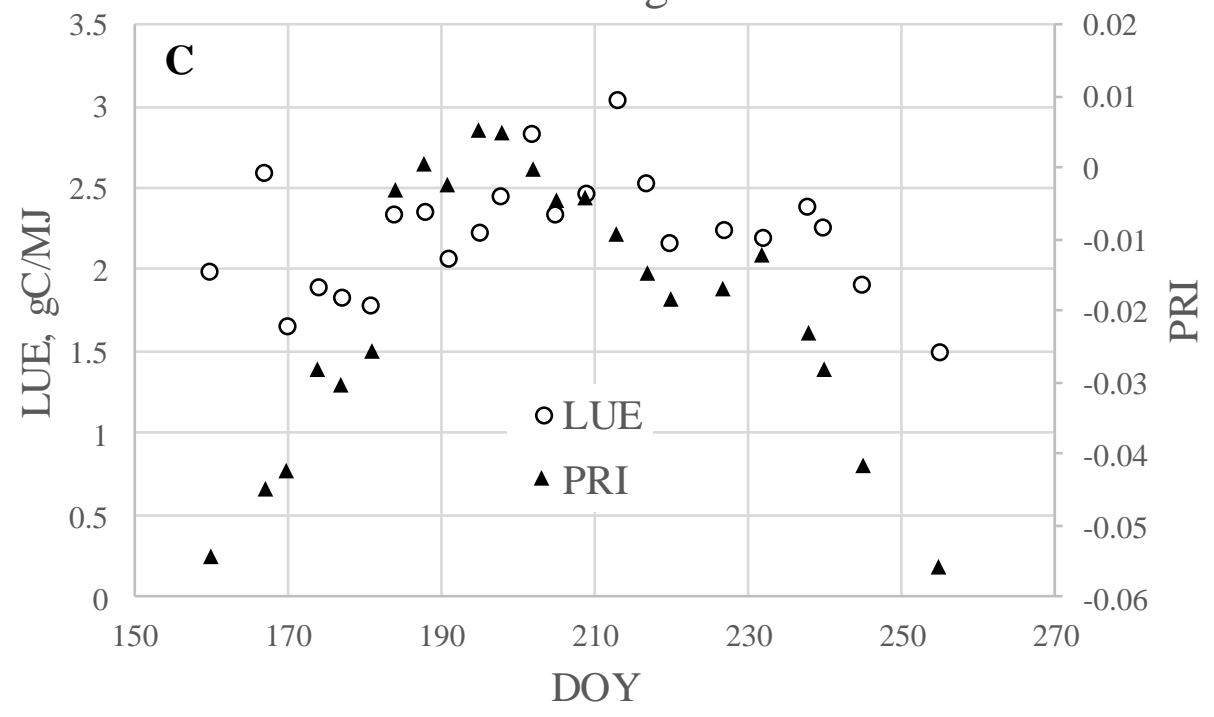


Figure 6D

Click here to download Figure: Fig6d.pdf

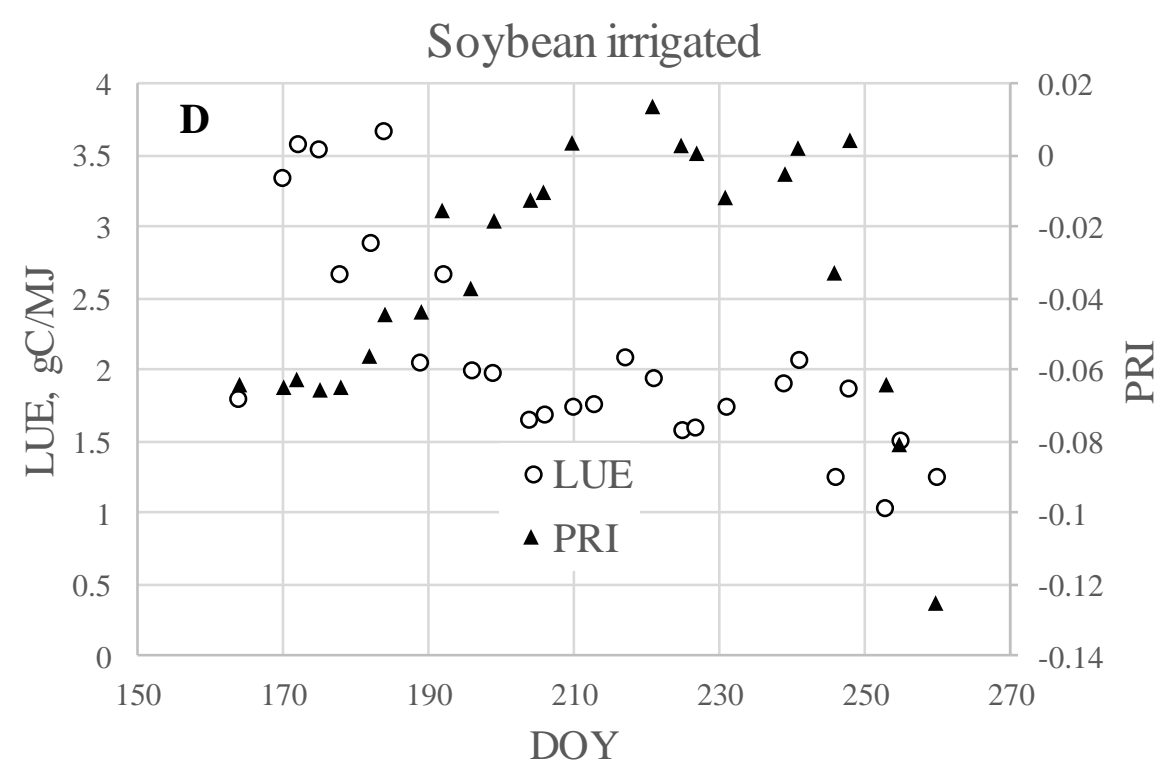


Figure 7A

Click here to download Figure: Fig7a.pdf

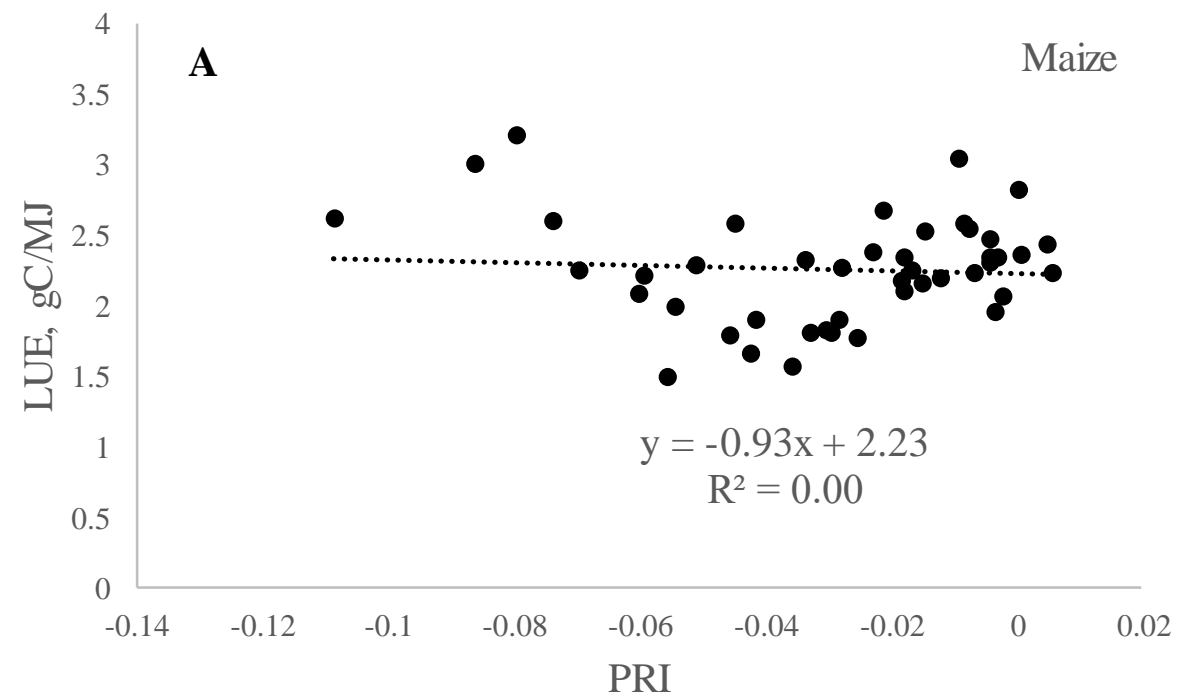




\section{Figure 7B}

Click here to download Figure: Fig7b.pdf

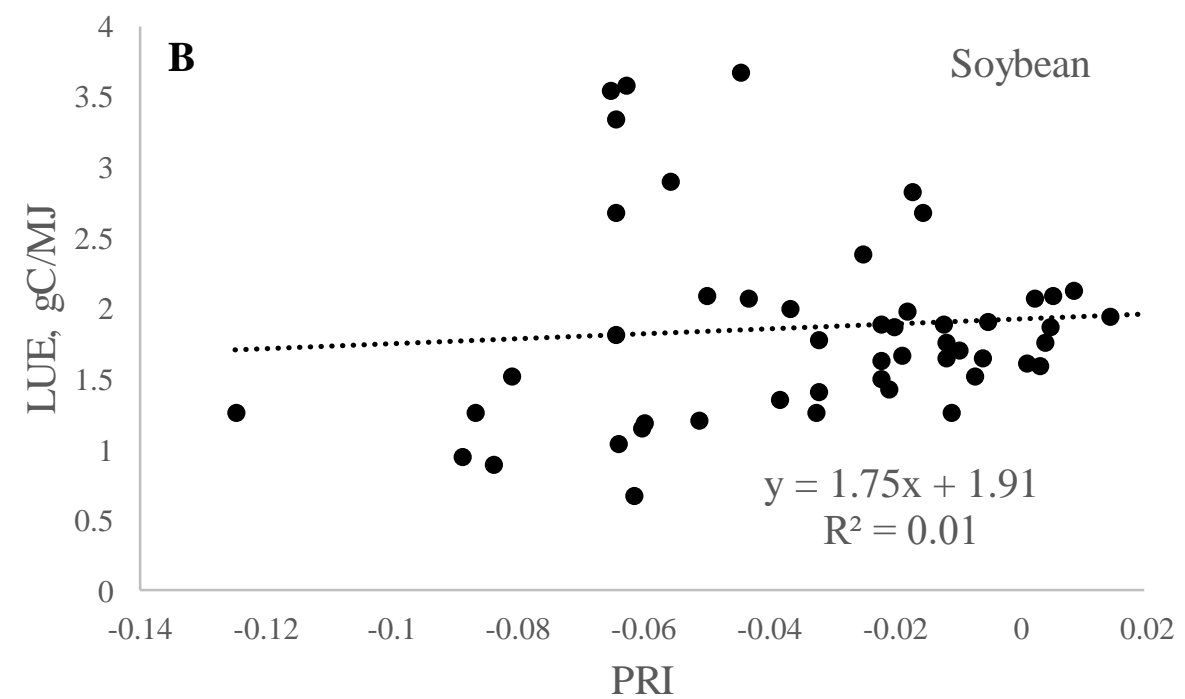




\section{Figure 7}

Click here to download Figure: Fig7c.pdf

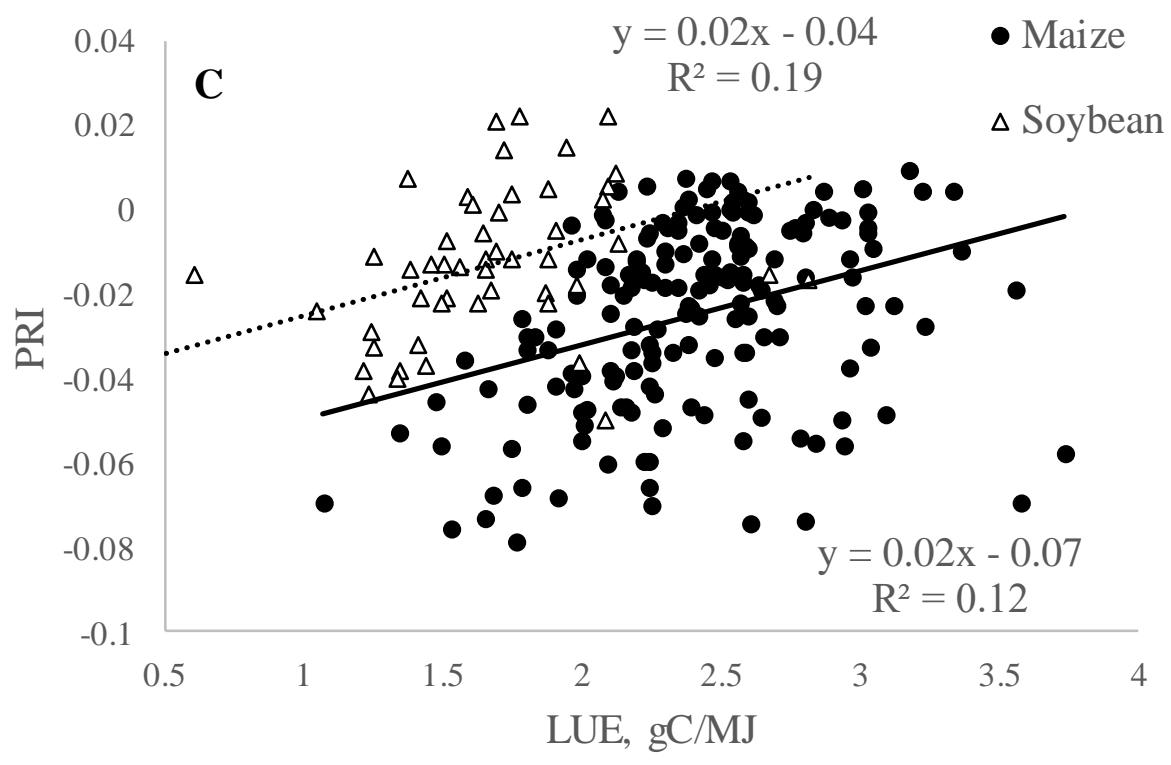


Click here to download Figure: Fig8a.pdf

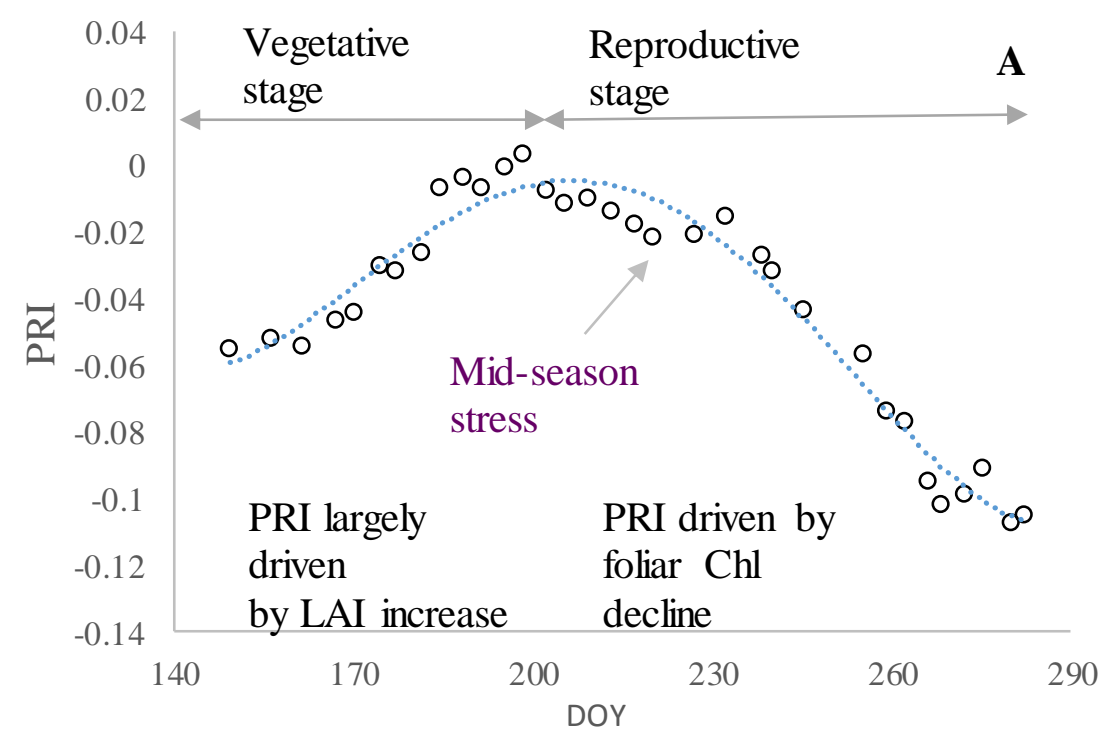


Click here to download Figure: Fig8b.pdf

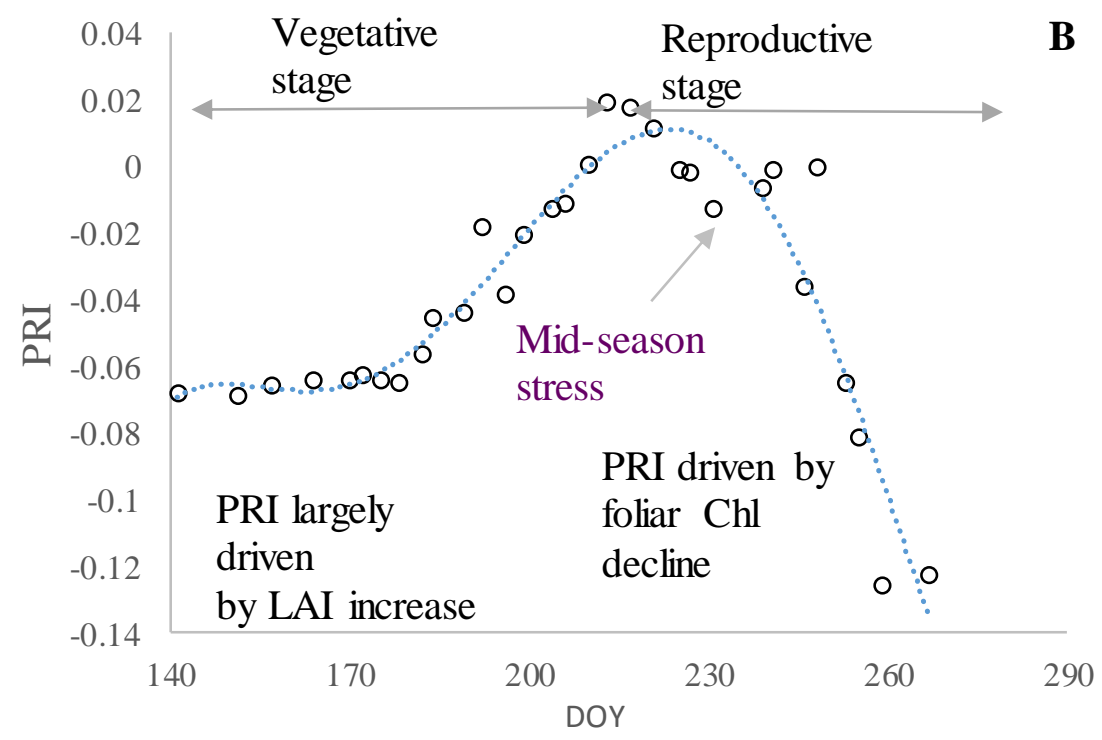


Figure 9A

Click here to download Figure: Fig9a.pdf

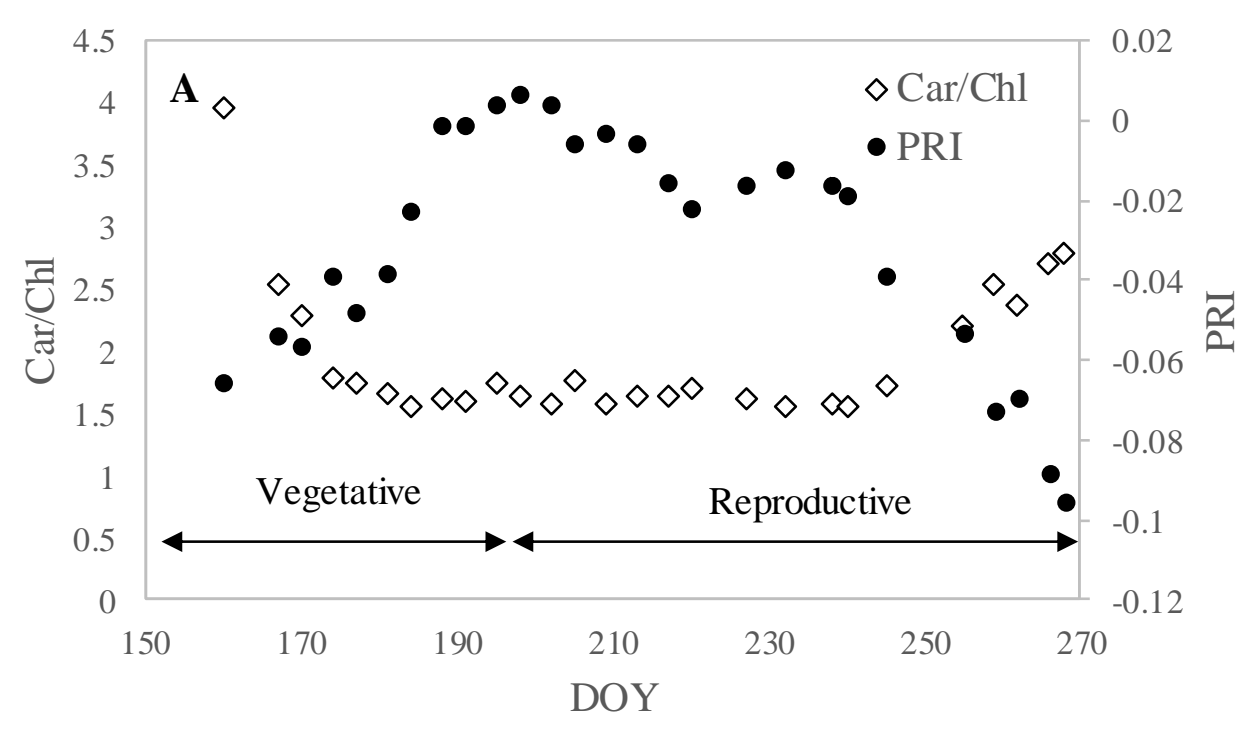




\section{gure 9B}

Click here to download Figure: Fig9b.pdf

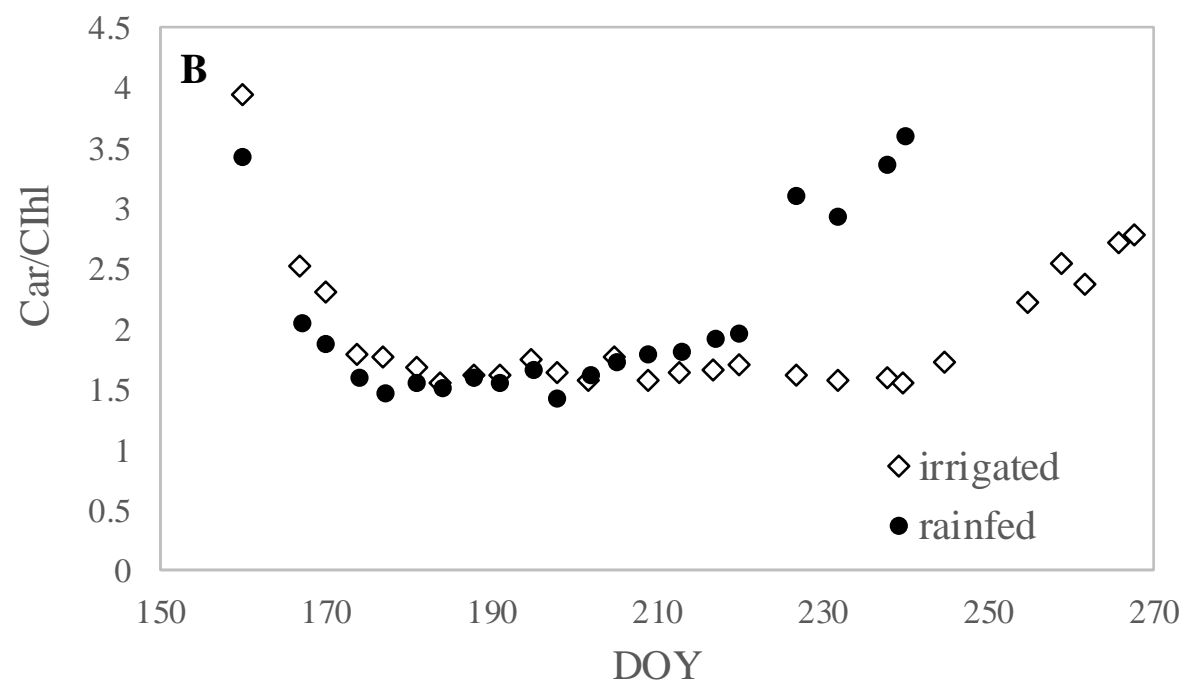


Click here to download Figure: Fig 10-new.pdf

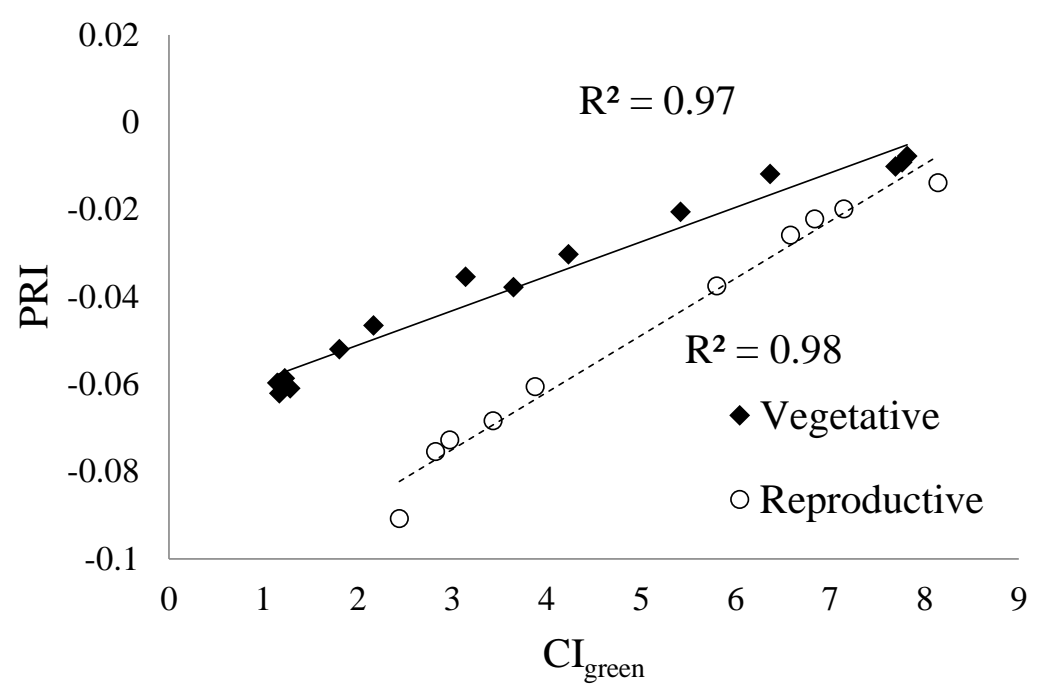


Click here to download Figure: Fig11a.pdf

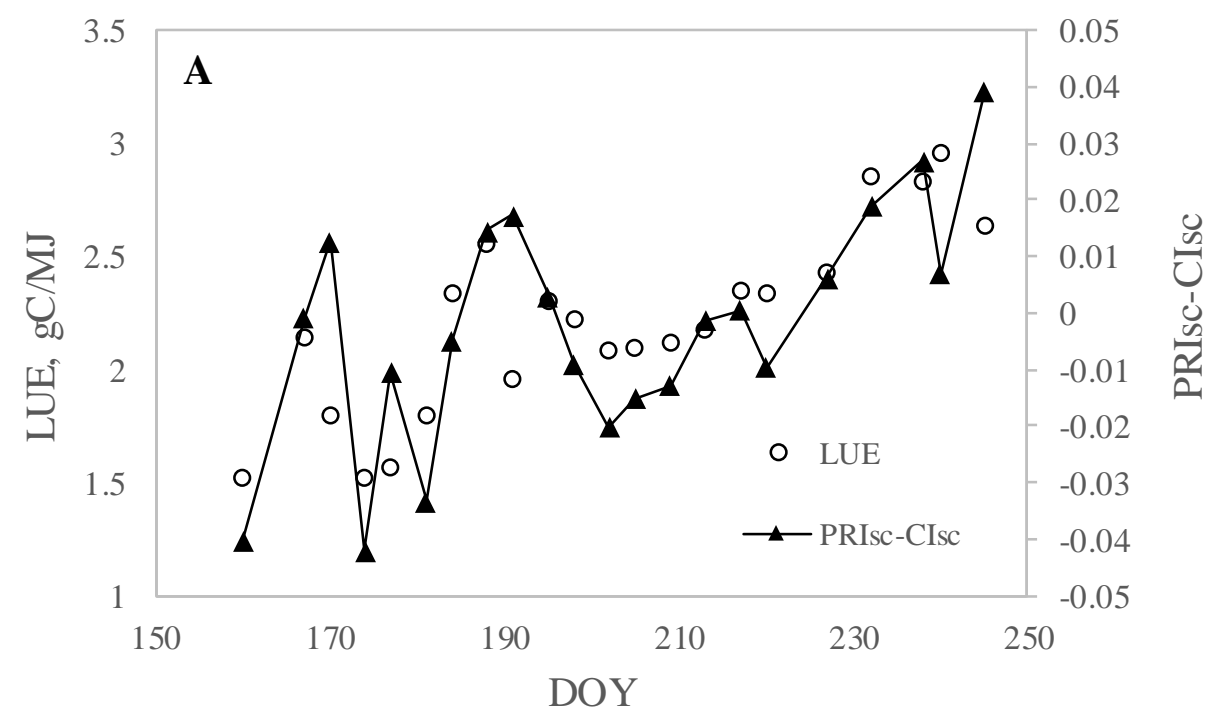




\section{Figure 11B}

Click here to download Figure: Fig11b.pdf

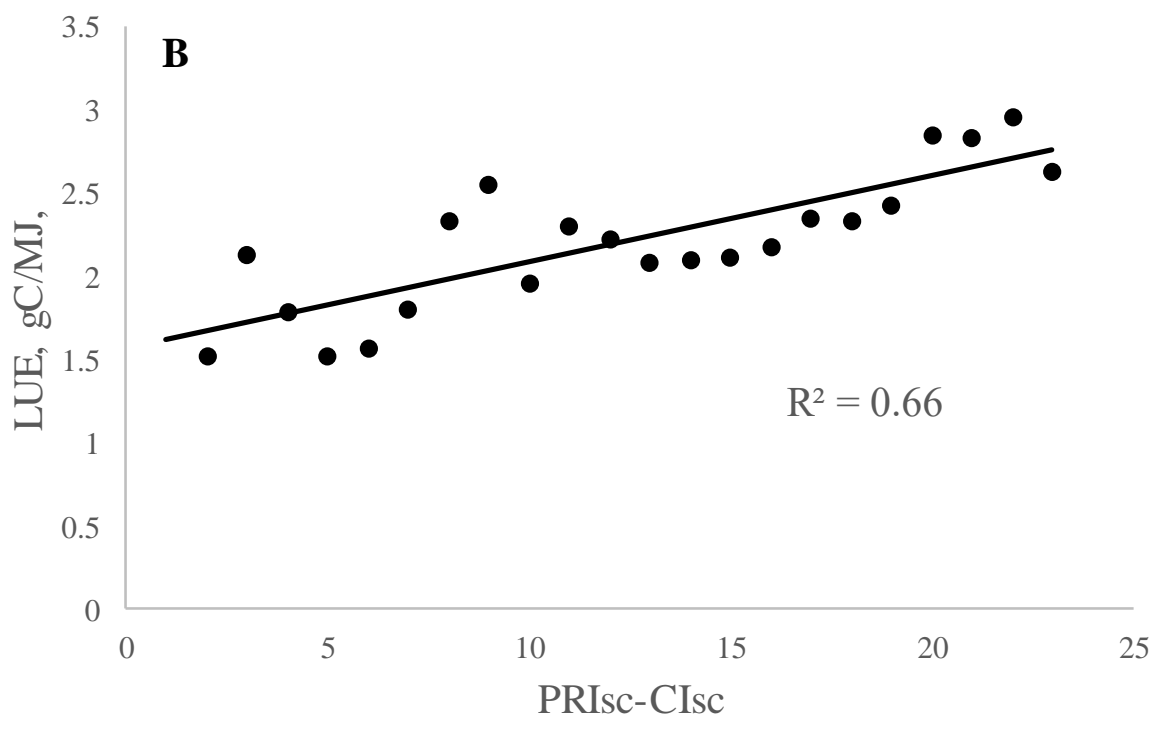

